\title{
SEAMHCRD deterministic compartmental model based on clinical stages of infection for COVID-19 pandemic in Sultanate of Oman
}

\section{Abraham Varghese}

Department of Information Technology, University of Technology and Applied Sciences

\section{Shajidmon Kolamban}

Department of Information Technology, University of Technology and Applied Sciences

Vinu Sherimon ( $\square$ vinusherimon@yahoo.com )

Department of Information Technology, University of Technology and Applied Sciences

Eduardo M. Lacap Jr.

Department of Information Technology, University of Technology and Applied Sciences

\section{Saad Salman Ahmed}

Department of Information Technology, University of Technology and Applied Sciences Jagath Prasad Sreedhar

Department of Information Technology, University of Technology and Applied Sciences

Hasina Al Harthy

Department of Information Technology, University of Technology and Applied Sciences

Huda Salim Al Shuaily

Department of Information Technology, University of Technology and Applied Sciences

\section{Research Article}

Keywords: COVID-19, mathematical model, differential equations, compartmental model, basic reproduction number, extended SIR model

Posted Date: October 12th, 2020

DOI: https://doi.org/10.21203/rs.3.rs-91097/v1

License: (c) (i) This work is licensed under a Creative Commons Attribution 4.0 International License. Read Full License

Version of Record: A version of this preprint was published at Scientific Reports on June 7th, 2021. See the published version at https://doi.org/10.1038/s41598-021-91114-5. 


\title{
SEAMHCRD deterministic compartmental model based on clinical stages of infection for COVID-19 pandemic in Sultanate of Oman
}

\author{
Abraham Varghese ${ }^{1}$, Shajidmon Kolamban ${ }^{1}$, Vinu Sherimon*2, Eduardo M. Lacap Jr. ${ }^{3}$, Saad Salman \\ Ahmed $^{1}$, Jagath Prasad Sreedhar ${ }^{3}$, Hasina Al Harthy ${ }^{4}$, Huda Salim Al Shuaily ${ }^{2}$ \\ ${ }^{1}$ Faculty of Mathematics, Department of Information Technology, University of Technology and Applied \\ Sciences, Muscat, Sultanate of Oman \\ ${ }^{2}$ Faculty of IT, Department of Information Technology, University of Technology and Applied Sciences, \\ Muscat, Sultanate of Oman \\ ${ }^{3}$ Faculty of Statistics, Department of Information Technology, University of Technology and Applied \\ Sciences, Muscat, Sultanate of Oman \\ ${ }^{4}$ Head of Research, Royal Hospital, Muscat, Sultanate of Oman
}

\begin{abstract}
The present novel corona virus (COVID-19) infection has engendered a worldwide crisis across the world in an enormous scale within a very short period. The effective solution for this pandemic is to recognize the nature and spread of the disease so that appropriate policies can be framed. Mathematical modelling is always at the forefront to understand and provide an adequate description about the transmission of any disease. In this research work, we have formulated a deterministic compartmental model (SEAMHCRD) including various stages of infection, such as Mild, Moderate, Severe and Critical to study the spreading of COVID19 and estimated the model parameters by fitting the model with the reported data of ongoing pandemic in Oman. The steady state, stability and final pandemic size of the model has been proved mathematically. The various transmission as well as transition parameters are estimated during the period from June $8^{\text {th }}-\mathrm{July} 30^{\text {th }}$, 2020. Based on the current estimated parameters, the pandemic size is also predicted for another 100 days. Sensitivity analysis is performed to identify the key model parameters, and corresponding basic reproduction number has been computed using Next Generation Matrix (NGM) method. As the value of basic reproduction number (R0) is 0.9761 during the period from June $8^{\text {th }}-$ July $30^{\text {th }}, 2020$, it is an indication for the policy makers to adopt appropriate remedial measures like social distancing and contact tracing to reduce the value of R0 to control the spread of the disease.
\end{abstract}

\section{Keywords}

COVID-19, mathematical model, differential equations, compartmental model, basic reproduction number, extended SIR model

\section{Introduction}

The novel coronavirus SARS-CoV-2 (COVID-19) is a spreadable disease that can be transmitted through contact and droplets $[1,2,3]$. The symptoms and signs of COVID-19 infection show up after roughly 5.2 days (development period) [4]. The most common symptoms are fever, cough, sore throat, and fatigue followed by other symptoms such as headache, diarrhoea, loss of smell, loss of taste, muscle pain etc. [4,5]. In critical cases, infected people may develop bronchitis, pneumonia, severe acute respiratory distress syndrome (SARDS), multi-organ failure, and may lead to death. On December 2019, the Wuhan city in China reported the first confirmed COVID-19 case; since then, the virus has spread universally. On March

*Correspondence to vinusherimon@yahoo.com 
$11^{\text {th }}, 2020$, the World Health Organization (WHO) announced COVID-19 epidemic as a pandemic [6]. The reported cases of COVID-19 have since been risen exponentially around the world reaching more than 200 nations [7]. As of September 11,2020, the total number of infected cases is $28,316,605$ and the total number of deaths is 913,284 all over the world [8].

Nowadays mathematical modeling has been well recognized as an epidemiological tool to combat many infectious diseases. Many researchers attempted to study and model infectious diseases which is an interdisciplinary field where biological knowledge behind the epidemics are equally important along with the mathematical framework. The very first mathematical model was traced back to the work of Daniel Bernoulli in the eighteenth century to estimate the life expectancy in smallpox epidemics [9]. Ross constructed a set of mathematical equations to demonstrate how malaria parasites were spread between mosquitoes and humans [10]. The model was later modified by the work of Macdonald [11] and finally became the well-known Ross-Macdonald models. The law of mass action was integrated into the Ross model by Kermack and McKendrick and they proposed new and modern compartmental models [12]. These models later became the most extensively used basic structures usually called compartment models in infectious disease modeling. In the conventional compartmental model, the whole population is split into groups according to the health status of people. For instance, the compartments of susceptible (S, healthy individuals), infectious (I, diseased and contagious individuals), and recovered (R, recovered individuals) as in SIR model [13]. SI, SIS, SIRS, SEIR(E-exposed but not infectious), SEIRS, MSIR(M-maternal immunity), MSEIR, and MSEIRS are other types of compartmental models that have been applied to many evolving communicable diseases like influenza and Ebola [14, 15].

Recently, Anastapoulou et al. proposed SIR model for predicting COVID-19 outbreak [16]. Casella constructed a controlled oriented SIR model that focusses the effect of delays and the outcome of different containment policies [17]. Giordano et al. developed a model called SIDARTHE model that predicts the effective control strategy of the COVID-19 pandemic situation in Italy [18]. It consists of eight classes such as susceptible (S), infected (I), diagnosed (D), ailing (A), recognized (R), threatened (T), healed (H) and extinct(E). The model differentiates between detected and non-detected among the infected cases and between life-threatening and non-life-threatening cases. Effect of lockdown, effect of testing etc. were simulated. The research results established that social-distancing, adequate number of tests and contact tracing will help to reduce the COVID-19 pandemic.

Researchers from Portugal and Spain proposed an adhoc compartmental model for COVID-19 in Wuhan [19]. In addition to susceptible, exposed, symptomatic, asymptomatic, and recovery, the research considered class of individuals such as fatality, hospitalized and super-spreaders. The basic reproduction number was computed to be 0.945 , less than 1 . So, the disease-free equilibrium was found to be stable. The sensitivity index of each of the parameters was calculated and the model was compared with the real data sets. The predicted model fits with the actual data of daily confirmed deaths.

The impact of social distancing and lockdown measures were studied in the research [20] where a compartmental SEIR model was proposed. The research recommended that the total cases can be reduced by $90 \%$ if proper countermeasures are carried out. The dynamic behaviour of the disease is studied in [21] by developing a mathematical model by including isolation class. As per the research findings, the main cause of the disease spread is the contact between people. So, isolation of infected people is highly recommended to reduce the spread.

In this work, we suggest a new compartmental model that extends classical SIR model by incorporating various infectious stage of COVID-19 epidemic in Sultanate of Oman for a period of 57 days. As of September 11, 2020, out of 88,337 confirmed cases in Sultanate of Oman, 4250 are active, 83,325 have recovered, and 762 is dead [8]. The rest of the paper is outlined as follows: - Section 2 explains the proposed model, the mathematical equations constructed and the analysis of the model. Section 3 presents the *Correspondence to vinusherimon@yahoo.com 
estimation of parameters, and the prediction of the pandemic in Oman. The sensitivity analysis of the model with respect to the infected cases, recovered cases and death cases is presented in Section 4. Conclusion and Future is presented in Section 5 followed by References.

\section{Materials and Methods}

In this research, we formulate the transmission mechanism of COVID-19 using a deterministic compartmental model. In order to formulate the mathematical model, we have divided total population into eight mutually exclusive compartments based on their disease status. The class Susceptible individuals (S) are those who have never been infected with and thus have no immunity against COVID-19. Susceptible individuals become exposed once they are infected with the disease. The Exposed individuals (E) are those who are in the infected stage, but not yet infectious to others. The class (A) of infected individuals are those with no symptom or mild symptom developed. These individuals may have symptoms like fever and cough but with normal chest X-ray result. These individuals may either improve or progress to the Moderate stage of the disease. The Moderate class (M) of individuals suffers with a moderate infection symptom like fever and cough and may even have mild pneumonia but do not need hospitalization. In this stage, it is likely to show the symptoms fever and cough and with chest X-ray result as Major bilateral abnormality, pneumonia or Infiltrations/patchy shadowing. These individuals may either improve or progress to the severe stage of the disease. The hospitalized individuals $(\mathrm{H})$ suffers from a severe infection and have severe pneumonia and need hospitalization. These individuals show symptoms of severe pneumonia that leads to dyspnea, respiratory frequency greater than or equal to 30 breaths/min at rest, blood oxygen saturation less than or equal to $93 \%$, partial pressure of arterial oxygen to fraction of inspired oxygen ratio less than or equal to 300 $\mathrm{mmHg}$, and/or lung infiltrates $>50 \%$ within 24 to 48 hours. Such cases require immediate hospitalization and supplemental oxygen. These individuals may either recover or progress to the critical stage of the disease. The class of critical (C) individuals are affected by a critical infection like respiratory failure, septic shock, and/or multiple organ dysfunction or failure and require treatment in an Intensive care unit (ICU), often with the requirement of a mechanical ventilation. These individuals may either recover or die suffering from the disease during time. The Recovered individuals $(\mathrm{R})$ are those who have recovered and are expected to be immune to future infection with COVID-19. The class of individuals (D) are those who have died because of COVID-19. Depending on the severity of the diseases like mild, moderate, severe and critical, the Infected people are sent to an appropriate COVID care centers or at home isolation. The authorities are monitoring their progress daily and takes appropriate actions [22].

\subsection{Model and Equations}

Fig. 1 depicts the various stages of the proposed compartment model.

\footnotetext{
*Correspondence to vinusherimon@yahoo.com
} 


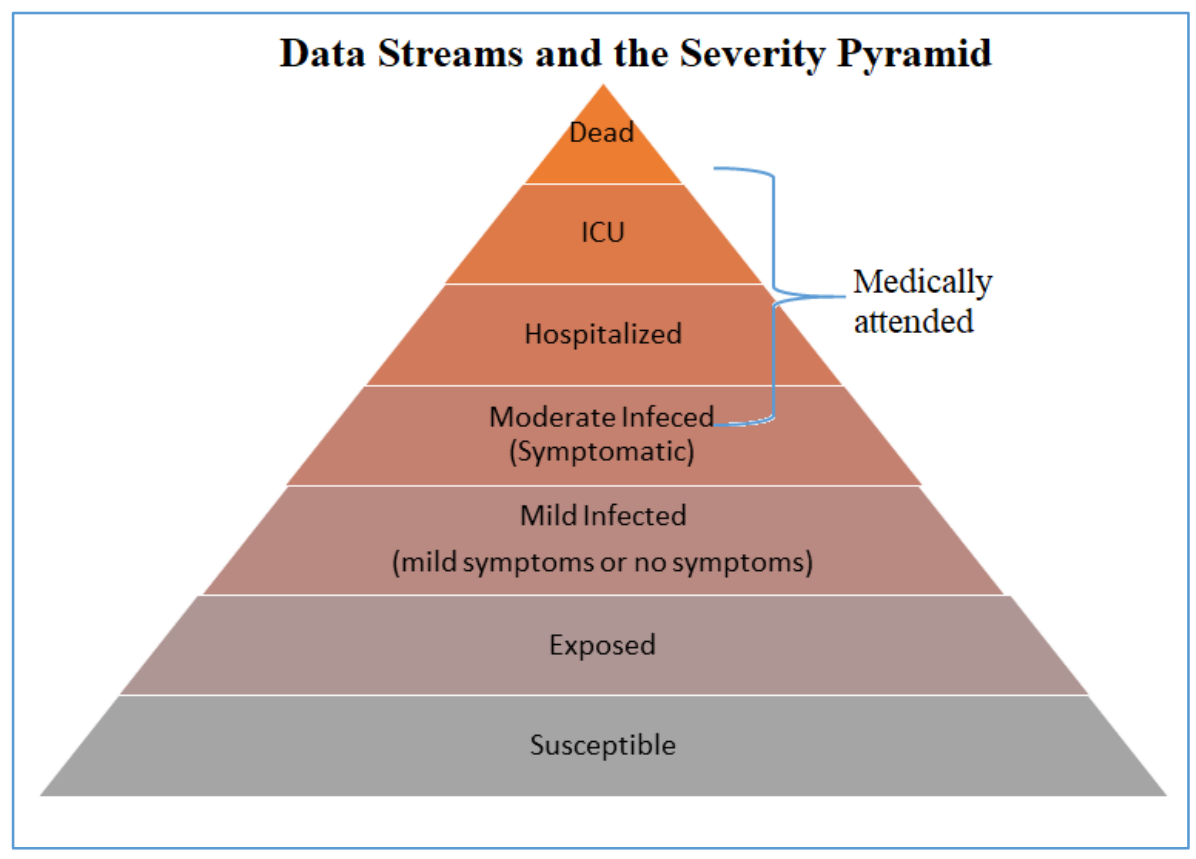

Figure 1. The different stages of the compartment model

At any time, $t$, total population $N(t)=S(t)+E(t)+A(t)+M(t)+H(t)+C(t)+R(t)+D(t)$. These 8 compartments are governed by 8 dynamic system of non-linear differential equations that vary with time, and nature of the solution and the stability of the system is investigated. Fig. 2 depicts the diagram of the overview of the model. The corresponding equations and the description of the various parameters involved are given in equation 1.1 .

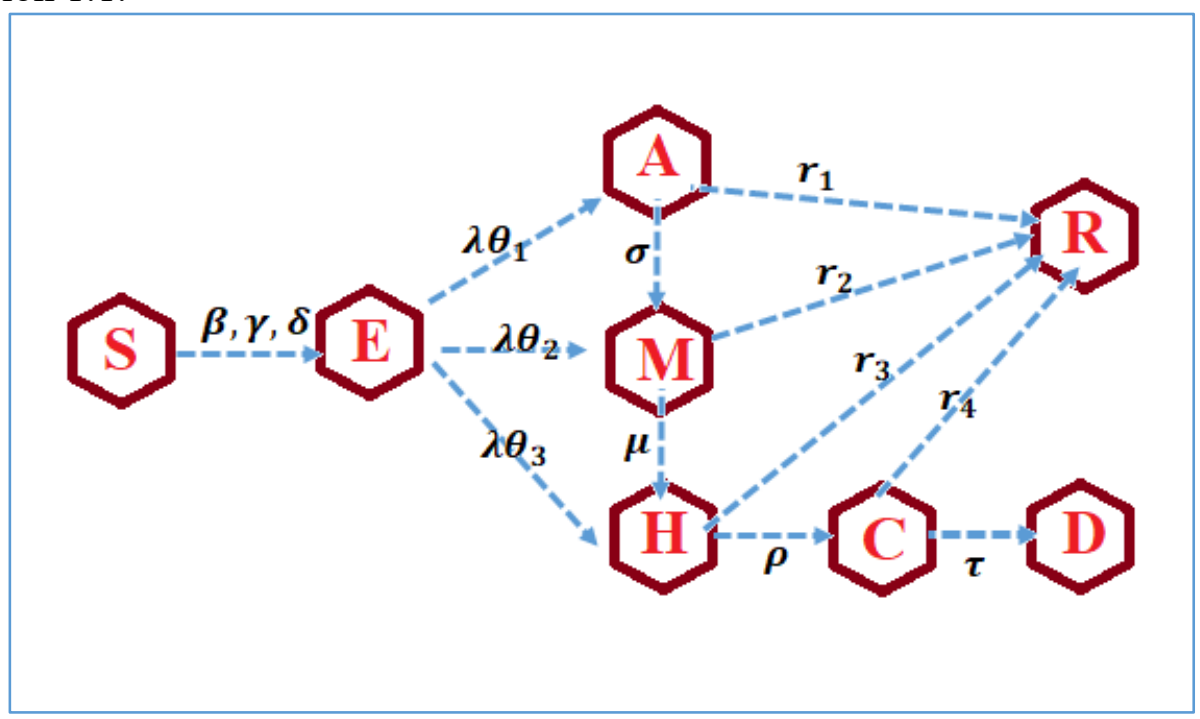

Figure 2. The overview of the model

$$
\begin{aligned}
& S^{\prime}(t)=-S(t)[\beta A(t)+\gamma M(t)+\delta H(t)] \\
& E^{\prime}(t)=S(t)[\beta A(t)+\gamma M(t)+\delta H(t)]-\lambda\left(\theta_{1}+\theta_{2}+\theta_{3}\right) E(t) \\
& A^{\prime}(t)=\lambda \theta_{1} E(t)-\left(\sigma+r_{1}\right) A(t) \\
& M^{\prime}(t)=\lambda \theta_{2} E(t)+\sigma A(t)-\left(\mu+r_{2}\right) M(t)
\end{aligned}
$$

*Correspondence to vinusherimon@yahoo.com 


$$
\begin{aligned}
& H^{\prime}(t)=\lambda \theta_{3} E(t)+\mu M(t)-\left(\rho+r_{3}\right) H(t) \\
& C^{\prime}(t)=\rho H(t)-\left(\tau+r_{4}\right) C(t) \\
& R^{\prime}(t)=r_{1} A(t)+r_{2} M(t)+r_{3} H(t)+r_{4} C(t) \\
& D^{\prime}(t)=\tau C(t)
\end{aligned}
$$

We choose $\theta_{3}=1-\left(\theta_{1}+\theta_{2}\right)$

Table 1 provides the description the parameter.

Table 1: Description of the parameter

\begin{tabular}{|l|l|l|}
\hline$\alpha$ & Transmission rate due to the contact with the asymptomatic exposed individuals & \\
\hline$\beta$ & $\begin{array}{l}\text { Transmission rate due to the contact with the asymptomatic/mild infected } \\
\text { individuals }\end{array}$ & $\begin{array}{l}\text { Transmission } \\
\text { parameters }\end{array}$ \\
\hline$\gamma$ & Transmission rate due to the contact with the symptomatic moderately infected & \\
\hline$\delta$ & Transmission rate due to the contact with the symptomatic severe infected & \\
\hline$\theta_{1}$ & Detection rate for asymptomatic/mild infected & \multirow{2}{*}{$\begin{array}{l}\text { Transition } \\
\text { parameters }\end{array}$} \\
\hline$\theta_{2}$ & Detection rate for symptomatic moderate infected & \\
\hline$\theta_{3}$ & Detection rate for symptomatic severe infected & \\
\hline$\sigma$ & Asymptomatic/mild infected become symptomatic moderately infected & \\
\hline$\mu$ & Symptomatic moderately infected become symptomatic severe infected & \\
\hline$\rho$ & Symptomatic severe infected become symptomatic critical infected & \\
\hline$\tau$ & Mortality rate for critically infected & \\
\hline$\lambda$ & Incubation period & \\
\hline$\varepsilon$ & Exit rate from $E_{N}$ & \\
\hline$r_{1}$ & Exit rate from $E_{T}$ & Recovery rate for asymptomatic/mild infected \\
\hline$r_{2}$ & Recovery rate for symptomatic moderate infected \\
\hline$r_{3}$ & Recovery rate for symptomatic severe infected & \\
\hline$r_{4}$ & Recovery rate for critical infection & \\
\hline
\end{tabular}

\subsection{Analysis of the model}

\subsubsection{Nonnegativity of solutions}

The model (1.1) is a bilinear system with eight differential equations. The system is positive, all the compartmental variables take non-negative values for $t \geq 0 . R(t)$ and $D(t)$ are cumulative variables.

Proposition 1: Consider a system $\mathrm{F}(\mathrm{t})=(\mathrm{S}, \mathrm{E}, \mathrm{A}, \mathrm{M}, \mathrm{H}, \mathrm{C}, \mathrm{R}, \mathrm{D})$ along with the initial conditions $F(0) \geq 0$ , then the solutions of (1.1) are non-negative for all $t \geq 0$

\section{Proof}

*Correspondence to vinusherimon@yahoo.com 
The integrating factor of first equation in (1.1) is $e^{\int^{t}(\beta A(\varphi)+\gamma M(\varphi)+\delta H(\varphi)) d \varphi}$

So, the solution is $S(t) e^{\int^{t}(\beta A(\varphi)+\gamma M(\varphi)+\delta H(\varphi)) d \varphi}=S(0)$

$S(t)=S(0)\left(e^{-\int_{0}^{t}(\beta A(\varphi)+\gamma M(\varphi)+\delta H(\varphi)) d \varphi}\right) \geq 0$

Similarly, we can establish other variables also. Thus $F(0) \geq 0$ for all $t \geq 0$.

The compartmental system satisfies mass conservative property and that can be checked easily from (1.1) $S^{\prime}(t)+E(t)+A^{\prime}(t)+M^{\prime}(t)+H^{\prime}(t)+C^{\prime}(t)+R^{\prime}(t)+D^{\prime}(t)=0$. Hence the total population is a constant.

When we consider each variable as the fraction of population, we can assume $S(t)+E(t)+A(t)+M(t)+H(t)+C(t)+R(t)+D(t)=1$, where 1 represents the total population.

Given an initial condition $S(0), E(0), A(0), M(0), H(0), C(0), R(0), D(0)$ summing to 1 , we can show that the variables converges to an equilibrium $\bar{S} \geq 0, \bar{E}=0, \bar{A}=0, \bar{M}=0, \bar{H}=0, \bar{C}=0, \bar{R} \geq 0, \bar{D} \geq 0$ with $\bar{S}+\bar{R}+\bar{D}=1$. So only the susceptible, recovered and death populations are eventually present. This means that the epidemic phenomenon has come to an end. All the possible equilibria are given by $(\bar{S}, 0,0,0,0,0,0, \bar{R}, \bar{D})$ with $\bar{S}+\bar{R}+\bar{D}=1$. In our model (1.1) the rate of the transmission parameter values $\beta, \gamma$ be reduced by strict social measurements. Also the rate of the main transition parameters $\sigma, \mu$ depends on the strictness of home isolation and quarantine process. Even if strict procedure is adopted in hospital admission, there may be a chance to spread the disease from the hospital. This is because long-time exposure to huge numbers of infected patients directly increments the risk of infection among healthcare workers. In addition to this, inadequate personal protection of healthcare workers, shortage of personal protective equipment (PPE), lack of organized training, practice, professional administration and guidance also may spread the disease. The increase in awareness of personal protection, enough PPE, and proper awareness would play a significant role in reducing the risk of infection among healthcare workers [23]. Therefore, by considering all these factors, we incorporated the compartment class $\mathrm{H}$ in our model in determining the spread of the disease, specifically in calculating the basic reproduction number.

The model has mainly three subsystems: The Susceptible individuals $S$ is the first. The infected and exposed individuals ( $E, A, M, H, C$ ) are in second which are non-zero in the transmission state and the recovery, and death $(R, D)$ are in third. The second subsystem is more important in the epidemic study. When this subsystem is zero the remaining variables are at equilibrium. The variables $R, D$ are monotonically increasing and converge to the values $\bar{R}, \bar{D}$ respectively and $S$ is monotonically decreasing and converges to $\bar{S}$ if and only if the second subsystem converges to zero.

\subsubsection{Basic Reproduction Number (R0)}

It is not possible to predict the endemic of the disease based on the increase or decrease in the number of cases alone. It is needed to find equilibria and linearize about each equilibrium to determine its stability to decide the disease pandemic or not. If an equilibrium with all susceptible population is unstable, then it is epidemic, and if it is asymptotically stable, then it is the end of pandemic. In order to get a meaningful realization of the situation, basic reproduction number (R0) is calculated which determines whether there is

*Correspondence to vinusherimon@yahoo.com 
an epidemic or not. The basic reproduction number (R0) is debatably the most significant quantity in infectious disease epidemiology. It is among the quantities most critically evaluated for evolving infectious diseases in epidemic states, and its value delivers insight when scheduling control interventions for conventional infections. It can be found easily whether the disease-free equilibrium of the system exists and is calculated from this system of equation after converting to next generation matrix (NGM).

If $\mathrm{R} 0<1$, the infection stops, and if $\mathrm{R} 0>1$, there is an epidemic. The basic reproduction number $\mathrm{R} 0$ is defined as the number of secondary infections caused by a single infective introduced into a wholly susceptible population of size $\mathrm{N} \approx \mathrm{S} 0$ over the course of the infection of this single infective. The basic reproduction number plays a vital role in controlling and spreading the disease. Diekmann et. al. [1] and Van den Driessche and Watmough [2] proposed generalized approach to determine the basic reproduction number which is known as the next generation matrix approach. The linearization of (1.1) the disease-free equilibrium $(\bar{S}, 0,0,0,0,0,0, \bar{R}, \bar{D})$ has the following matrix form

The infectious from (1.1) sub-system can be written as

$$
\begin{aligned}
& E^{\prime}(t)=S(t)[\beta A(t)+\gamma M(t)+\delta H(t)]-\lambda\left(\theta_{1}+\theta_{2}+\theta_{3}\right) E(t) \\
& A^{\prime}(t)=\lambda \theta_{1} E(t)-\left(\sigma+r_{1}\right) A(t) \\
& M^{\prime}(t)=\lambda \theta_{2} E(t)+\sigma A(t)-\left(\mu+r_{2}\right) M(t) \\
& H^{\prime}(t)=\lambda \theta_{3} E(t)+\mu M(t)-\left(\rho+r_{3}\right) H(t)
\end{aligned}
$$

The Jacobian matrix from (1.2) is

$$
J_{I}=\left[\begin{array}{cccc}
-p_{1} & \beta & \gamma & \delta \\
\theta_{1} & -p_{2} & 0 & 0 \\
\theta_{2} & \sigma & -p_{3} & 0 \\
\theta_{3} & 0 & \mu & -p_{4}
\end{array}\right]
$$

where $p_{1}=\lambda\left(\theta_{1}+\theta_{2}+\theta_{3}\right)=\lambda \quad, \quad p_{2}=\sigma+r_{1} \quad, \quad p_{3}=\mu+r_{2} \quad, \quad p_{4}=\rho+r_{3} \quad, \quad p_{5}=\tau+r_{4}$

Now the Jacobian matrix is decomposed into two matrices (transmission matrix and Transition matrix)

$$
T=\left[\begin{array}{llll}
0 & \beta & \gamma & \delta \\
0 & 0 & 0 & 0 \\
0 & 0 & 0 & 0 \\
0 & 0 & 0 & 0
\end{array}\right] \quad \Sigma=\left[\begin{array}{cccc}
-p_{1} & 0 & 0 & 0 \\
\theta_{1} & -p_{2} & 0 & 0 \\
\theta_{2} & \sigma & -p_{3} & 0 \\
\theta_{3} & 0 & \mu & -p_{4}
\end{array}\right]
$$

The NGM with classical domain is denoted by Dc. Here, we assume an auxiliary matrix E of the form:

$$
E=\left[\begin{array}{llll}
1 & 0 & 0 & 0 \\
0 & 0 & 0 & 0 \\
0 & 0 & 0 & 0 \\
0 & 0 & 0 & 0
\end{array}\right] .
$$

Now 


$$
D_{C}=-E^{\prime} T \Sigma^{-1} E=\left[\begin{array}{crrr}
\frac{\beta \theta_{1}}{p_{2}}+\frac{\gamma \sigma \theta_{1}}{p_{2} p_{3}}+\frac{\gamma \theta_{2}}{p_{3}}+\frac{\delta \sigma \mu \theta_{1}}{p_{2} p_{3} p_{4}}+\frac{\delta \mu \theta_{2}}{p_{3} p_{4}}+\frac{\delta \theta_{3}}{p_{4}} & 0 & 0 & 0 \\
0 & 0 & 0 & 0 \\
0 & 0 & 0 & 0 \\
0 & 0 & 0 & 0
\end{array}\right]
$$

From this, the basic reproduction number by considering the classical domain matrix is the spectral radius of the NGM

$$
R_{0}=\operatorname{trace}\left(D_{C}\right)=\frac{\beta \theta_{1}}{p_{2}}+\frac{\gamma \theta_{2}}{p_{3}}+\frac{\delta \theta_{3}}{p_{4}}+\frac{\gamma \sigma \theta_{1}}{p_{2} p_{3}}+\frac{\delta \mu \theta_{2}}{p_{3} p_{4}}+\frac{\delta \sigma \mu \theta_{1}}{p_{2} p_{3} p_{4}}
$$

\subsubsection{Steady State Analysis}

Proposition 2: If $R_{0}>1$ then the disease-free equilibrium is unstable, and it is stable if $R_{0}<1$

\section{Proof}

The dynamical matrix of the linearized system around the equilibrium is

$$
J=\left[\begin{array}{cccccccc}
0 & 0 & -\beta \bar{S} & -\gamma \bar{S} & -\delta \bar{S} & 0 & 0 & 0 \\
0 & p_{1} & \beta \bar{S} & \gamma \bar{S} & \delta \bar{S} & 0 & 0 & 0 \\
0 & \lambda \theta_{1} & -p_{2} & 0 & 0 & 0 & 0 & 0 \\
0 & \lambda \theta_{2} & \sigma & -p_{3} & 0 & 0 & 0 & 0 \\
0 & \lambda \theta_{3} & 0 & \mu & -p_{4} & 0 & 0 & 0 \\
0 & 0 & 0 & 0 & \rho & -p_{5} & 0 & 0 \\
0 & 0 & r_{1} & r_{2} & r_{3} & r_{4} & 0 & 0 \\
0 & 0 & 0 & 0 & 0 & \tau & 0 & 0
\end{array}\right]
$$

The matrix (1.4) has three null eigenvalues, and five eigenvalues are roots of the equation.

$$
\begin{aligned}
P(s) \equiv & \frac{\beta \lambda \theta_{1}}{\left(s+p_{1}\right)\left(s+p_{2}\right)}+\frac{\gamma \sigma \lambda \theta_{1}}{\left(s+p_{1}\right)\left(s+p_{2}\right)\left(s+p_{3}\right)}+\frac{\gamma \lambda \theta_{2}}{\left(s+p_{1}\right)\left(s+p_{3}\right)} \\
& +\frac{\delta \sigma \mu \lambda \theta_{1}}{\left(s+p_{1}\right)\left(s+p_{2}\right)\left(s+p_{3}\right)\left(s+p_{4}\right)}+\frac{\delta \mu \lambda \theta_{2}}{\left(s+p_{1}\right)\left(s+p_{3}\right)\left(s+p_{4}\right)}+\frac{\delta \lambda \theta_{3}}{\left(s+p_{1}\right)\left(s+p_{4}\right)}-1=0
\end{aligned}
$$

Then $P(0)=R_{0}-1$

Now consider the following cases

\section{Case 1}

Suppose $R_{0}>1$. Then $P(0)>0$. Also $P(s) \rightarrow-1$ as $s \rightarrow \infty$. Since $P(s)$ is a continuous function of $s$, hence by Bolzano theorem on continuous function implies that $P\left(s_{i}\right)=0$ for some $s_{i}>0$, at least one eigenvalue must be positive. So, in this case, the equilibrium is unstable. 


\section{Case II}

Suppose $R_{0}<1$. Then $P(0)<0$.

Assume that $P(s)=0$ has a root of the form $x+i y$ where $x, y \in R$ and $x \geq 0$. Then $P(x+i y)=0$

$$
\begin{aligned}
& \text { Now }|P(x+i y)+1| \leq \frac{\beta \lambda \theta_{1}}{\left|\left(s+p_{1}\right)\right|\left|\left(s+p_{2}\right)\right|}+\frac{\gamma \sigma \lambda \theta_{1}}{\left|\left(s+p_{1}\right)\right|\left(s+p_{2}\right)\left|\left(s+p_{3}\right)\right|}+\frac{\gamma \lambda \theta_{2}}{\left|\left(s+p_{1}\right)\right|\left|\left(s+p_{3}\right)\right|} \\
& +\frac{\delta \sigma \mu \lambda \theta_{1}}{\left|\left(s+p_{1}\right)\right|\left|\left(s+p_{2}\right)\right|\left|\left(s+p_{3}\right)\right|\left|\left(s+p_{4}\right)\right|}+\frac{\delta \mu \lambda \theta_{2}}{\left|\left(s+p_{1}\right)\right|\left|\left(s+p_{3}\right)\right|\left|\left(s+p_{4}\right)\right|}+\frac{\delta \lambda \theta_{3}}{\left|\left(s+p_{1}\right)\right|\left|\left(s+p_{4}\right)\right|} \\
& \leq \frac{\beta \lambda \theta_{1}}{\left(x+p_{1}\right)\left(x+p_{2}\right)}+\frac{\gamma \sigma \lambda \theta_{1}}{\left(x+p_{1}\right)\left(x+p_{2}\right)\left(x+p_{3}\right)}+\frac{\gamma \lambda \theta_{2}}{\left(x+p_{1}\right)\left(x+p_{3}\right)} \\
& +\frac{\delta \sigma \mu \lambda \theta_{1}}{\left(x+p_{1}\right)\left(x+p_{2}\right)\left(x+p_{3}\right)\left(x+p_{4}\right)}+\frac{\delta \mu \lambda \theta_{2}}{\left(x+p_{1}\right)\left(x+p_{3}\right)\left(x+p_{4}\right)}+\frac{\delta \lambda \theta_{3}}{\left(x+p_{1}\right)\left(x+p_{4}\right)} \\
& \leq \frac{\beta \lambda \theta_{1}}{p_{1} p_{2}}+\frac{\gamma \sigma \lambda \theta_{1}}{p_{1} p_{2} p_{3}}+\frac{\gamma \lambda \theta_{2}}{p_{1} p_{3}}+\frac{\delta \sigma \mu \lambda \theta_{1}}{p_{1} p_{2} p_{3} p_{4}}+\frac{\delta \mu \lambda \theta_{2}}{p_{1} p_{3} p_{4}}+\frac{\delta \lambda \theta_{3}}{p_{1} p_{4}}=R_{0}<1
\end{aligned}
$$

Which implies $1<1$. This is clearly a contradiction. Hence all roots of the equation $P(s)=0$ have the form $x+i y$ where $x, y \in R$ and $x<0$. Thus, all eigenvalues of the coefficient matrix have negative real part and this case equilibrium is stable, the solution of (1.1) die out exponentially [9].

\subsubsection{Final pandemic size relations}

Proposition 3: For positive initial conditions, the limit values $\bar{S}=\lim _{t \rightarrow \infty} S(t), \bar{R}=\lim _{t \rightarrow \infty} R(t)$ and $\bar{D}=\lim _{t \rightarrow \infty} D(t)$ are given by

$$
\begin{aligned}
& l_{0}+R_{0}(S(0)-\bar{S})=\log \left(\frac{S(0)}{\bar{S}}\right) \\
& \bar{R}=R(0)+l_{R}+R_{R}(S(0)-\bar{S}) \\
& \bar{D}=D(0)+f_{D}+R_{D}(S(0)-\bar{S})
\end{aligned}
$$

where $l_{0}=-a^{T} B^{-1} x(0), l_{R}=-b^{T} B^{-1} x(0), R_{R}=-b^{T} B^{-1} D, l_{D}=-c^{T} B^{-1} x(0)$ and $R_{D}=-c^{T} B^{-1} D$

\section{Proof}

Define $x=[E A M H C]^{T}$, we can write the subsystem as 
$x^{\prime}(t)=B x(t)+D u(t)=\left[\begin{array}{ccccc}-p_{1} & 0 & 0 & 0 & 0 \\ \theta_{1} & -p_{2} & 0 & 0 & 0 \\ \theta_{2} & \sigma & -p_{3} & 0 & 0 \\ \theta_{3} & 0 & \mu & -p_{4} & 0 \\ 0 & 0 & 0 & \rho & -p_{5}\end{array}\right] x(t)+\left[\begin{array}{l}1 \\ 0 \\ 0 \\ 0 \\ 0 \\ 0\end{array}\right] u(t)$

$y_{S}(t)=a^{T} x(t)=\left[\begin{array}{lllll}0 & \beta & \gamma & \delta & 0\end{array}\right] x(t)$

$y_{R}(t)=b^{T} x(t)=\left[\begin{array}{lllll}0 & r_{1} & r_{2} & r_{3} & r_{4}\end{array}\right] x(t)$

$y_{D}(t)=c^{T} x(t)=\left[\begin{array}{lllll}0 & 0 & 0 & 0 & \tau\end{array}\right] x(t)$

$u(t)=S(t) y_{S}(t)$

where $p_{1}=\lambda\left(\theta_{1}+\theta_{2}+\theta_{3}\right) \quad, \quad p_{2}=\sigma+r_{1} \quad, \quad p_{3}=\mu+r_{2} \quad, \quad p_{4}=\rho+r_{3} \quad, \quad p_{5}=\tau+r_{4}$

and the other variables in the differential equation (1.1) can be written as

$$
\begin{aligned}
& S^{\prime}(t)=-S(t) y_{S}(t) \\
& R^{\prime}(t)=y_{R}(t) \\
& D^{\prime}(t)=y_{D}(t)
\end{aligned}
$$

The number of infectives always approaches zero and the number of susceptible always approaches a positive limit as $t \rightarrow \infty$

From (1.8) $\quad S^{\prime}(t)=-S(t) y_{S}(t)$

$$
\begin{aligned}
-\frac{S^{\prime}(t)}{S(t)}=y_{S}(t) & \Rightarrow-\int_{0}^{\infty} \frac{S^{\prime}(t)}{S(t)}=\int_{0}^{\infty} y_{S}(t) \\
& \Rightarrow \int_{0}^{\infty} y_{S}(t)=\log \left(\frac{S(0)}{\bar{S}}\right)
\end{aligned}
$$

From (1.7)

$$
\begin{aligned}
& \int_{0}^{\infty} x^{\prime}(\varphi) d \varphi=B \int_{0}^{\infty} x(\varphi) d \varphi+D \int_{0}^{\infty} u(\varphi) d \varphi \\
& x(\infty)-x(0)=B \int_{0}^{\infty} x(\varphi) d \varphi+D \int_{0}^{\infty} S(\varphi) y_{S}(\varphi) d \varphi \quad \text { from (1.12) }
\end{aligned}
$$

Since $x(\infty)=0$

$$
\begin{aligned}
& -x(0)=B \int_{0}^{\infty} x(\varphi) d \varphi-D \int_{0}^{\infty} S^{\prime}(\varphi) d \varphi \\
& -x(0)=B \int_{0}^{\infty} x(\varphi) d \varphi-D(\bar{S}-S(0))
\end{aligned}
$$

*Correspondence to vinusherimon@yahoo.com 
Pre multiply by $a^{T} B^{-1}$ and using (1.9) we have

$$
\begin{array}{ll}
-a^{T} B^{-1} x(0)=a^{T} B^{-1} B \int_{0}^{\infty} x(\varphi) d \varphi-a^{T} B^{-1} D(\bar{S}-S(0)) \\
-a^{T} B^{-1} x(0)=\int_{0}^{\infty} y_{S}(\varphi) d \varphi-a^{T} B^{-1} D(\bar{S}-S(0)) \\
l_{0}=\log \left(\frac{S(0)}{\bar{S}}\right)+R_{0}(\bar{S}-S(0)) & \text { from }(1.16)
\end{array}
$$

where $l_{0}=-a^{T} B^{-1} x(0)$ and it is easy to show that $R_{0}=-a^{T} B^{-1} D$. So

$$
l_{0}+R_{0}(S(0)-\bar{S})=\log \left(\frac{S(0)}{\bar{S}}\right)
$$

The expressions (1.6) and (1.7) can be proved easily by pre-multiplying (1.17) by $b^{T} B^{-1}$ and $c^{T} B^{-1}$ respectively.

Note that with an initial condition $[E(0)>0, A(0)=M(0)=H(0)=C(0)=0]$, we can compute $l_{0}$ as $l_{0}=R_{0} E(0)$ and for long term prediction it has to be adjusted by considering $l_{0}=-a^{T} B^{-1} x\left(t_{0}\right)$ where $\mathrm{B}$ includes new parameter values. In (1.5) also, it is adjusted accordingly by $S\left(t_{0}\right)$.

\subsection{Extension of the model by including Exposed period}

The study on COVID-19 reveals the fact that transmission of disease happens in various stages, namely symptomatic transmission, pre-symptomatic transmission and asymptomatic transmission. In a symptomatic transmission case, the infected persons develop signs and symptoms compatible with COVID-19 virus infection and transfers to the contacted person(s). Specifically, symptomatic transmission denotes the transmission from a person while they are suffering from the symptoms and this transmission takes place through respiratory droplets or by contact with the contaminated objects and surfaces [30,31,32,33,34,35]. Research studies on virus infection reveals that flaking of COVID-19 virus is peak in upper respiratory tract (nose and throat) early during the disease, which is, within the first three days from the start of symptoms $[24,25,26]$. Preliminary data proposes that people may be more infectious around the time of beginning of the symptoms as compared to the later stages of the disease [36,37,38].

But in the case of Pre-symptomatic transmission, there is an incubation period (on average 5-6 days and can be extended up to 14 days) which is the duration between first day of infection and symptom onset, is, however can be up to 14 days. During this period some infected persons can be contagious. Therefore, transmission from a pre-symptomatic case can occur up to a certain extent before symptom onset. The study $[24,25,26,27,28,29]$ reveals that some people can be tested positive for COVID-19 from 1-3 days prior to the development of symptoms. Thus, it is probable that people infected with COVID-19 could transmit the virus before any significant symptoms develop. It is very significant to understand that pre-symptomatic transmission still needs the virus to be spread through infectious droplets or through touching contaminated surfaces.

While in Asymptomatic transmission, a person is infected with COVID-19, but does not develop symptoms. Asymptomatic transmission refers to the transmission of the virus from a person, who does not develop

*Correspondence to vinusherimon@yahoo.com 
symptoms. Even though there is no solid report on asymptomatic transmission, we cannot avoid the possibility that it may occur. In some countries, the asymptomatic cases have been reported as part of the contact tracing efforts. WHO frequently monitors all evolving evidence about this critical topic and delivers updates when more information becomes available.

So in our model (1.1), the exposed classes is divided into two separate classes namely $E_{N}$ defines no symptom or transmission and $E_{T}$ with no symptom but can transmit the virus ("pre-symptomatic transmission"), based on the various studies [24,25,26,27,28,29] about COVID-19 pre-symptomatic infection,. The rate of exit from $E_{N}$ is $\varepsilon$ and from $E_{T}$ is $v$. Accordingly, the modified diagram by expanding exposed case is given in Figure 3. The modified equation of (1.1) is also given in (1.18).
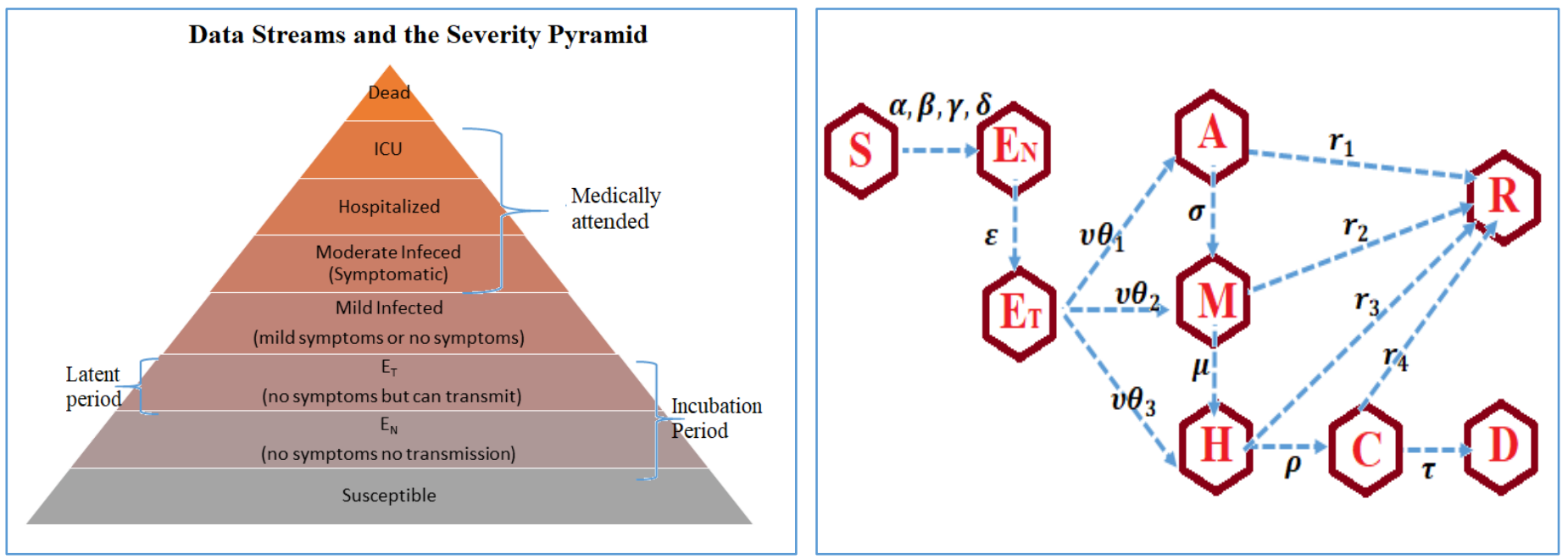

Figure 3. The extension of the model by including exposed period

$$
\begin{aligned}
& S^{\prime}(t)=-S(t)\left[\alpha E_{T}+\beta A(t)+\gamma M(t)+\delta H(t)\right] \\
& E^{\prime}(t)=S(t)\left[\alpha E_{T}+\beta A(t)+\gamma M(t)+\delta H(t)\right]-\varepsilon E_{N}(t) \\
& E_{T}(t)=\varepsilon E_{N}(t)-v\left(\theta_{1}+\theta_{2}+\theta_{3}\right) E_{T}(t) \\
& A^{\prime}(t)=\lambda \theta_{1} E_{T}(t)-\left(\sigma+r_{1}\right) A(t) \\
& M^{\prime}(t)=\lambda \theta_{2} E_{T}(t)+\sigma A(t)-\left(\mu+r_{2}\right) M(t) \\
& H^{\prime}(t)=\lambda \theta_{3} E_{T}(t)+\mu M(t)-\left(\rho+r_{3}\right) H(t) \\
& C^{\prime}(t)=\rho H(t)-\left(\tau+r_{4}\right) C(t) \\
& R^{\prime}(t)=r_{1} A(t)+r_{2} M(t)+r_{3} H(t)+r_{4} C(t) \\
& D^{\prime}(t)=\tau C(t)
\end{aligned}
$$

We choose $\theta_{3}=1-\left(\theta_{1}+\theta_{2}\right)$

Accordingly, the basic reproduction number using next generation matrix can be written as

$$
R_{0}=\frac{\alpha}{p_{1}}+\frac{\beta \theta_{1}}{p_{2}}+\frac{\gamma \theta_{2}}{p_{3}}+\frac{\delta \theta_{3}}{p_{4}}+\frac{\gamma \sigma \theta_{1}}{p_{2} p_{3}}+\frac{\delta \mu \theta_{2}}{p_{3} p_{4}}+\frac{\delta \sigma \mu \theta_{1}}{p_{2} p_{3} p_{4}}
$$

\footnotetext{
*Correspondence to vinusherimon@yahoo.com
} 
where $p_{1}=v\left(\theta_{1}+\theta_{2}+\theta_{3}\right)=v \quad, \quad p_{2}=\sigma+r_{1} \quad, \quad p_{3}=\mu+r_{2} \quad, \quad p_{4}=\rho+r_{3} \quad, \quad p_{5}=\tau+r_{4}$

The model including exposed period was implemented in MATLAB and findings are depicted in section 3.

\section{Results}

The simulation of the extended model is implemented in MATLAB. The data for this study has been taken from the official Tarassud Plus application, Ministry of Health, Oman [39] and the sources [39,40]. The data of Oman during the period June $4^{\text {th }}, 2020$ to July 30,2020 (about 57 days) has been used for this study. During this period, the country has undergone lockdown, partial lockdown and relaxation. The given data is categorized into 9 compartments (S, E, Et, A, M, H, C, R.D) as mentioned in the methodology section 2.1. The data for the study is given in Table 2 .

Table 2. Oman Dataset

\begin{tabular}{|c|c|c|c|c|c|c|c|c|c|c|}
\hline Date & $\mathbf{S}$ & EN & ET & $\mathbf{A}$ & $\mathbf{M}$ & H & $\mathrm{C}$ & $\mathbf{R}$ & D & $\mathbf{A C}$ \\
\hline 04 June 2020 & 5087015 & 3779 & 1512 & 2103 & 8411 & 226 & 58 & 3451 & 67 & 10798 \\
\hline 05 June 2020 & 5085870 & 4047 & 1619 & 2255 & 9021 & 227 & 60 & 3451 & 72 & 11563 \\
\hline 06 June 2020 & 5084484 & 4373 & 1749 & 2435 & 9740 & 251 & 67 & 3451 & 72 & 12493 \\
\hline 07 June 2020 & 5083195 & 4675 & 1870 & 2598 & 10393 & 290 & 75 & 3451 & 75 & 13356 \\
\hline 08 June 2020 & 5082466 & 4764 & 1906 & 2651 & 10603 & 283 & 75 & 3793 & 81 & 13612 \\
\hline 09 June 2020 & 5081582 & 4887 & 1955 & 2717 & 10870 & 291 & 85 & 4152 & 83 & 13963 \\
\hline 10 June 2020 & 5080643 & 5066 & 2026 & 2819 & 11277 & 293 & 85 & 4329 & 84 & 14474 \\
\hline 11 June 2020 & 5080179 & 4635 & 1854 & 2568 & 10274 & 308 & 92 & 6623 & 89 & 13242 \\
\hline 12 June 2020 & 5078943 & 4720 & 1888 & 2617 & 10468 & 309 & 92 & 7489 & 96 & 13486 \\
\hline 13 June 2020 & 5077465 & 5057 & 2023 & 2808 & 11231 & 315 & 94 & 7530 & 99 & 14448 \\
\hline 14 June 2020 & 5075829 & 5223 & 2089 & 2902 & 11608 & 313 & 100 & 8454 & 104 & 14923 \\
\hline 15 June 2020 & 5074805 & 5209 & 2084 & 2892 & 11570 & 317 & 104 & 9533 & 108 & 14883 \\
\hline 16 June 2020 & 5074461 & 4923 & 1969 & 2727 & 10907 & 327 & 105 & 11089 & 114 & 14066 \\
\hline 17 June 2020 & 5073602 & 4958 & 1983 & 2740 & 10962 & 362 & 102 & 11797 & 116 & 14166 \\
\hline 18 June 2020 & 5073221 & 4702 & 1881 & 2591 & 10363 & 378 & 103 & 13264 & 119 & 13435 \\
\hline 19 June 2020 & 5072302 & 4750 & 1900 & 2616 & 10464 & 389 & 102 & 13974 & 125 & 13571 \\
\hline 20 June 2020 & 5071364 & 4780 & 1912 & 2630 & 10518 & 411 & 99 & 14780 & 128 & 13658 \\
\hline 21 June 2020 & 5070395 & 4826 & 1930 & 2658 & 10633 & 396 & 101 & 15552 & 131 & 13788 \\
\hline 22 June 2020 & 5068426 & 5086 & 2034 & 2805 & 11219 & 407 & 100 & 16408 & 137 & 14531 \\
\hline 23 June 2020 & 5066891 & 5241 & 2096 & 2891 & 11566 & 421 & 97 & 17279 & 140 & 14975 \\
\hline 24 June 2020 & 5065529 & 5398 & 2159 & 2981 & 11924 & 417 & 100 & 17972 & 142 & 15422 \\
\hline 25 June 2020 & 5063764 & 5683 & 2273 & 3143 & 12571 & 417 & 107 & 18520 & 144 & 16238 \\
\hline 26 June 2020 & 5062552 & 5740 & 2296 & 3174 & 12694 & 426 & 105 & 19482 & 153 & 16399 \\
\hline 27 June 2020 & 5061618 & 5751 & 2300 & 3177 & 12710 & 431 & 113 & 20363 & 159 & 16431 \\
\hline 28 June 2020 & 5060247 & 5875 & 2350 & 3249 & 12997 & 423 & 118 & 21200 & 163 & 16787 \\
\hline 29 June 2020 & 5059492 & 5764 & 2306 & 3186 & 12745 & 423 & 115 & 22422 & 169 & 16469 \\
\hline 30 June 2020 & 5058482 & 5764 & 2306 & 3183 & 12732 & 437 & 117 & 23425 & 176 & 16469 \\
\hline
\end{tabular}

*Correspondence to vinusherimon@yahoo.com 


\begin{tabular}{|c|c|c|c|c|c|c|c|c|c|c|}
\hline 01 July 2020 & 5057174 & 5896 & 2358 & 3260 & 13041 & 426 & 120 & 24162 & 185 & 16847 \\
\hline 02 July 2020 & 5055713 & 5967 & 2387 & 3303 & 13212 & 420 & 114 & 25318 & 188 & 17049 \\
\hline 03 July 2020 & 5054086 & 6148 & 2459 & 3401 & 13606 & 447 & 113 & 26169 & 193 & 17567 \\
\hline 04 July 2020 & 5052728 & 6277 & 2511 & 3473 & 13894 & 452 & 116 & 26968 & 203 & 17935 \\
\hline 05 July 2020 & 5051600 & 6317 & 2527 & 3494 & 13975 & 458 & 121 & 27917 & 213 & 18048 \\
\hline 06 July 2020 & 5049885 & 6430 & 2572 & 3555 & 14222 & 465 & 129 & 29146 & 218 & 18371 \\
\hline 07 July 2020 & 5048916 & 6221 & 2488 & 3436 & 13746 & 464 & 127 & 31000 & 224 & 17773 \\
\hline 08 July 2020 & 5047610 & 6289 & 2516 & 3474 & 13898 & 469 & 128 & 32005 & 233 & 17969 \\
\hline 09 July 2020 & 5045847 & 6464 & 2586 & 3575 & 14298 & 466 & 129 & 33021 & 236 & 18468 \\
\hline 10 July 2020 & 5043627 & 6701 & 2680 & 3703 & 14811 & 501 & 130 & 34225 & 244 & 19145 \\
\hline 11 July 2020 & 5042520 & 6718 & 2687 & 3709 & 14835 & 517 & 133 & 35255 & 248 & 19194 \\
\hline 12 July 2020 & 5040974 & 6881 & 2752 & 3798 & 15194 & 525 & 143 & 36098 & 257 & 19660 \\
\hline 13 July 2020 & 5038318 & 7232 & 2893 & 4000 & 15998 & 519 & 146 & 37257 & 259 & 20663 \\
\hline 14 July 2020 & 5036613 & 7458 & 2983 & 4129 & 16516 & 514 & 149 & 37987 & 273 & 21308 \\
\hline 15 July 2020 & 5034630 & 7675 & 3070 & 4252 & 17007 & 530 & 139 & 39038 & 281 & 21928 \\
\hline 16 July 2020 & 5033173 & 7768 & 3107 & 4299 & 17197 & 549 & 149 & 40090 & 290 & 22194 \\
\hline 17 July 2020 & 5031431 & 7856 & 3142 & 4347 & 17386 & 555 & 157 & 41450 & 298 & 22445 \\
\hline 18 July 2020 & 5030131 & 7848 & 3139 & 4337 & 17349 & 574 & 164 & 42772 & 308 & 22424 \\
\hline 19 July 2020 & 5029014 & 7819 & 3128 & 4318 & 17271 & 585 & 165 & 44004 & 318 & 22339 \\
\hline 20 July 2020 & 5026990 & 8023 & 3209 & 4436 & 17744 & 574 & 170 & 45150 & 326 & 22924 \\
\hline 21 July 2020 & 5025493 & 8030 & 3212 & 4438 & 17753 & 582 & 169 & 46608 & 337 & 22942 \\
\hline 22 July 2020 & 5023669 & 8147 & 3259 & 4507 & 18027 & 577 & 165 & 47922 & 349 & 23276 \\
\hline 23 July 2020 & 5023714 & 7330 & 2932 & 4037 & 16147 & 589 & 169 & 51349 & 355 & 20942 \\
\hline 24 July 2020 & 5022822 & 7149 & 2860 & 3937 & 15750 & 568 & 170 & 53007 & 359 & 20425 \\
\hline 25 July 2020 & 5021755 & 7149 & 2860 & 3938 & 15751 & 570 & 167 & 54061 & 371 & 20426 \\
\hline 26 July 2020 & 5020659 & 7113 & 2845 & 3922 & 15688 & 545 & 167 & 55299 & 384 & 20322 \\
\hline 27 July 2020 & 5019942 & 6873 & 2749 & 3782 & 15126 & 552 & 177 & 57028 & 393 & 19637 \\
\hline 28 July 2020 & 5019450 & 6620 & 2648 & 3641 & 14565 & 528 & 181 & 58587 & 402 & 18915 \\
\hline 29 July 2020 & 5019274 & 6271 & 2508 & 3442 & 13769 & 522 & 184 & 60240 & 412 & 17917 \\
\hline 30 July 2020 & 5018978 & 6061 & 2424 & 3324 & 13295 & 511 & 187 & 61421 & 421 & 17317 \\
\hline
\end{tabular}

Based on the public data $[39,40]$, the situation in Oman at the end of May was not very severe. Muscat governorate reported more cases compared to other governorates. From the beginning itself, the Oman government has imposed strict measurements to control the disease. Oman Supreme committee has taken a good decision to close the main containment zone, Muscat governorate by April 10 which resulted in the reduction of the transmission rate. By April 29, 2020, the government lifted the restriction on travel inside the Governorate except in and out of Muscat governorate. More number of random tests were conducted in the main containment zones of Muscat governorate such as Muttrah, Seeb, Muscat Province and Al Amerat. It was made compulsory to wear masks in public places and thermal imaging was also done while entering majority of the shops in Muscat. The entry to shops were restricted to people with a temperature more than $37.5^{0}$ Celsius, and children of age less than 12 years of old were also not permitted. These decisions were a part of several measures broadcasted by the municipality as per the decision number 199/2020, which lists *Correspondence to vinusherimon@yahoo.com 
out 15 safety measures to be realized by the commercial establishments. Fines were also imposed on those who violates the rule. Lockdown in Muscat province, including the capital Muscat was lifted entirely on Friday, May 29, as the government begins easing the containment measures in place, nationwide. Additionally, at the end of May 2020, the government announced that at least 50 percent of public sector employees will resume working from their offices from Sunday, May 31.

We investigated the model parameters and corresponding effective reproduction number R0 during the period June $4^{\text {th }}$ to July $30^{\text {th }}$ when the country has undergone various intervened measures to control the disease.

\subsection{Parameter Estimation}

Mathematical models are useful in capturing patterns in data, thereby predicting the nature of pandemic to take right policy to control it. Hence it is very essential to find out the best fit parameters that give the closest correspondence between model predictions and data. The parameter estimation is done based on parameterized nonlinear functions which solves the $\min \left(\sum \| F\left(x_{i}-y_{i} \|^{2}\right)\right.$, where $F\left(x_{i}\right)$ is a nonlinear function and $y_{i}$ is data. The parameters for each period are chosen in such a way that it gives the minimum value for R0.

Fig. 4 shows the R0 over different period, and active cases versus R0. Fig. 5 shows the various transmission parameters over a period from June to August based on the fitted data'.
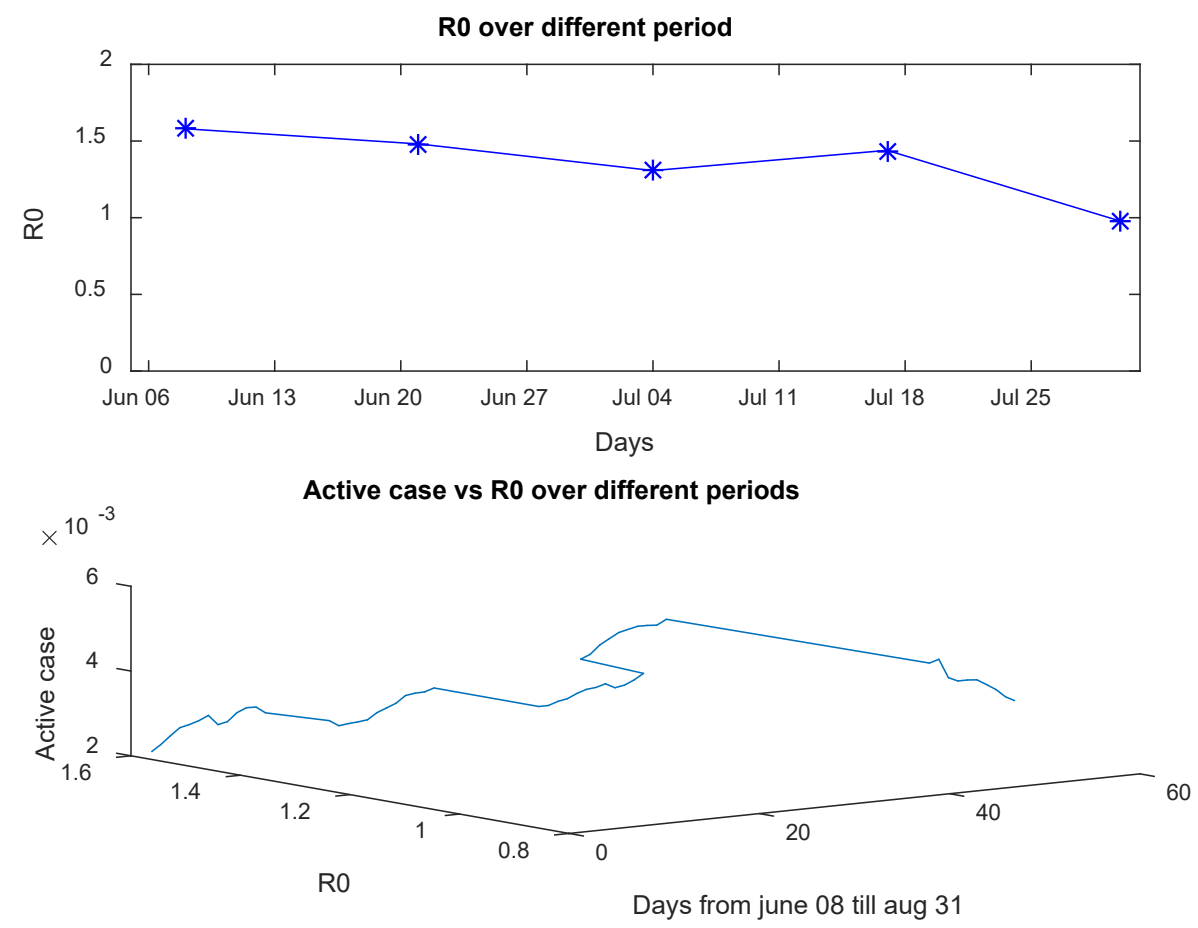

Figure 4. R0 and Active case vs Time

\footnotetext{
*Correspondence to vinusherimon@yahoo.com
} 

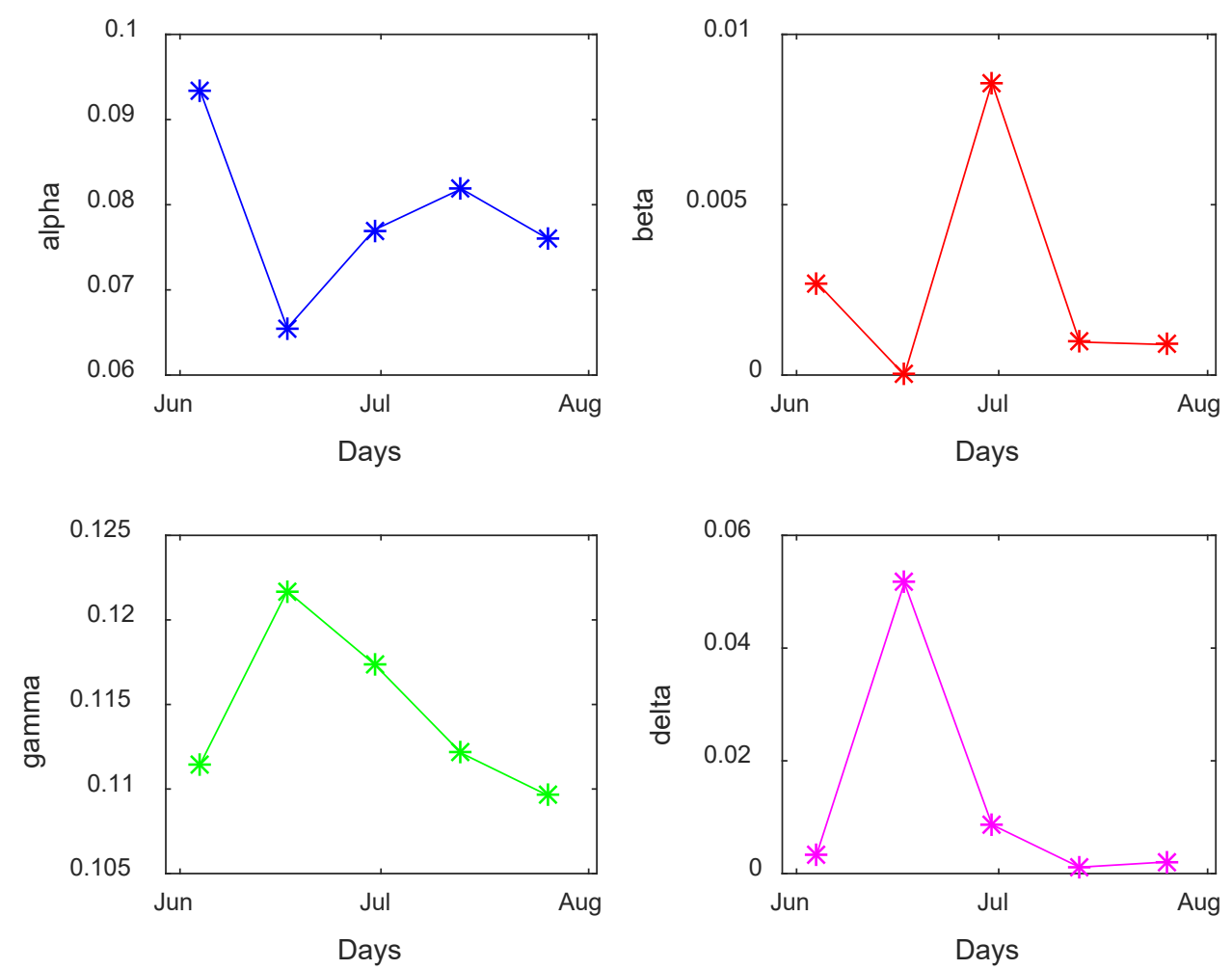

Figure 5. The transmission parameters vs time

\section{- $\quad$ Period 1 (4 ${ }^{\text {th }}$ June $-15^{\text {th }}$ June 2020)}

The estimated parameters from the model are, $\alpha=0.0934, \beta=0.0027, \gamma=0.1115, \delta=0.0034, \sigma=$ $0.0439, \mu=0.0363, \rho=0.0249, \tau=0.0100, \mathrm{r}_{1}=0.0745, \mathrm{r}_{2}=0.0364, \mathrm{r}_{3}=0.0281, \mathrm{r}_{4}=0.0227, \boldsymbol{\theta}_{1}=$ $0.4032, \boldsymbol{\theta}_{2}=0.9101, \boldsymbol{\theta}_{3}=0.0352$. The corresponding reproduction number is $\mathrm{R} 0=1.5802$.

- $\quad$ Period $2\left(16^{\text {th }}\right.$ June- $27^{\text {th }}$ June 2020)

The estimated parameters from the model in the given period are : $\alpha=0.0655, \beta=3.12 \mathrm{e}-06, \gamma=0.1217$, $\delta=0.0515, \sigma=0.10449, \mu=0.0516, \rho=0.0267, \tau=0.00999, \mathrm{r}_{1}=0.04296, \mathrm{r}_{2}=0.0809, \mathrm{r}_{3}=0.02769$, $\mathrm{r}_{4}=0.0155, \boldsymbol{\theta}_{1}=0.313, \boldsymbol{\theta}_{2}=0.855, \boldsymbol{\theta}_{3}=0.0126$. The corresponding reproduction number is $\mathrm{R} 0=1.4811$.

- Period 3(28 ${ }^{\text {th }}$ June-10 $^{\text {th }}$ July 2020)

The estimated parameters are from the model are : $\alpha=0.0770, \beta=0.00858, \gamma=0.11738, \delta=0.00866$, $\sigma=0.0805, \mu=0.0276, \rho=0.0260, \tau=0.00304, \mathrm{r}_{1}=0.04538, \mathrm{r}_{2}=0.0689, \mathrm{r}_{3}=0.02557, \mathrm{r}_{4}=02.53 \mathrm{e}-$ $05, \boldsymbol{\theta}_{1}=0.2984, \boldsymbol{\theta}_{2}=0.739, \boldsymbol{\theta}_{3}=0.000341$. The corresponding reproduction number is $\mathrm{R} 0=1.3071$.

- $\quad$ Period 4 (11 $^{\text {th }}$ July-20 $^{\text {th }}$ July 2020)

During the period the resulting parameter value estimates are : $\alpha=0.0818, \beta=0.000969, \gamma=0.1121, \delta$ $=0.00112, \sigma=0.00952, \mu=0.0109, \rho=0.02679, \tau=0.00999, \mathrm{r}_{1}=0.0591, \mathrm{r}_{2}=0.05591, \mathrm{r}_{3}=0.02823$, $\mathrm{r}_{4}=0.00089, \boldsymbol{\theta}_{1}=0.2278, \boldsymbol{\theta}_{2}=0.7479, \boldsymbol{\theta}_{3}=9.59 \mathrm{e}-05$. The corresponding R0 is 1.4392 .

*Correspondence to vinusherimon@yahoo.com 
- $\quad$ Period $5\left(21^{\text {st }}\right.$ July - 30 ${ }^{\text {th }}$ July 2020)

At the end of this period, the estimates are $\alpha=0.07597, \beta=0.000893, \gamma=0.10960, \delta=0.00205, \sigma=$ $0.03988, \mu=0.01678, \rho=0.02577, \tau=0.00999, \mathrm{r}_{1}=0.0455, \mathrm{r}_{2}=0.09789, \mathrm{r}_{3}=0.02673, \mathrm{r}_{4}=2.571 \mathrm{e}-08$, $\boldsymbol{\theta}_{1}=0.2661, \boldsymbol{\theta}_{2}=0.7753, \boldsymbol{\theta}_{3}=0.01952$. The corresponding R0 is 0.9761 .

\subsection{Prediction of Pandemic size}

The data from June $4^{\text {th }}$ to July $30^{\text {th }}$ (57 days) is fitted using 9 differential equations as given in $(1.18)$ and the corresponding parameters are estimated. Fig 6 a depicts the projection of infected case, recovered case and deaths, and Fig. $6 \mathrm{~b}$ depicts that of mild, moderate and altogether.
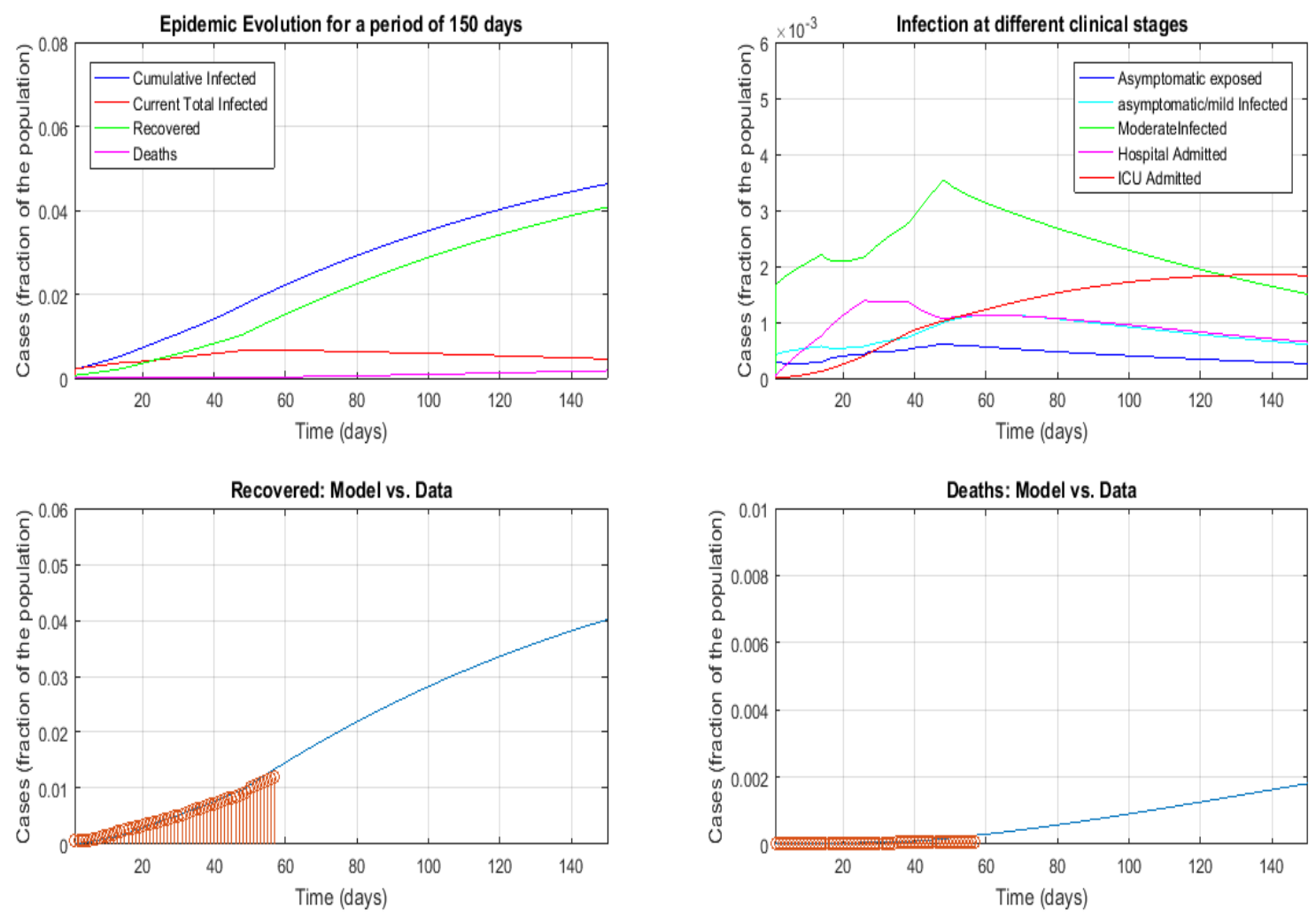

Figure 6 a. The pandemic size of different clinical stage vs time - infected case, recovered case and death case

*Correspondence to vinusherimon@yahoo.com 

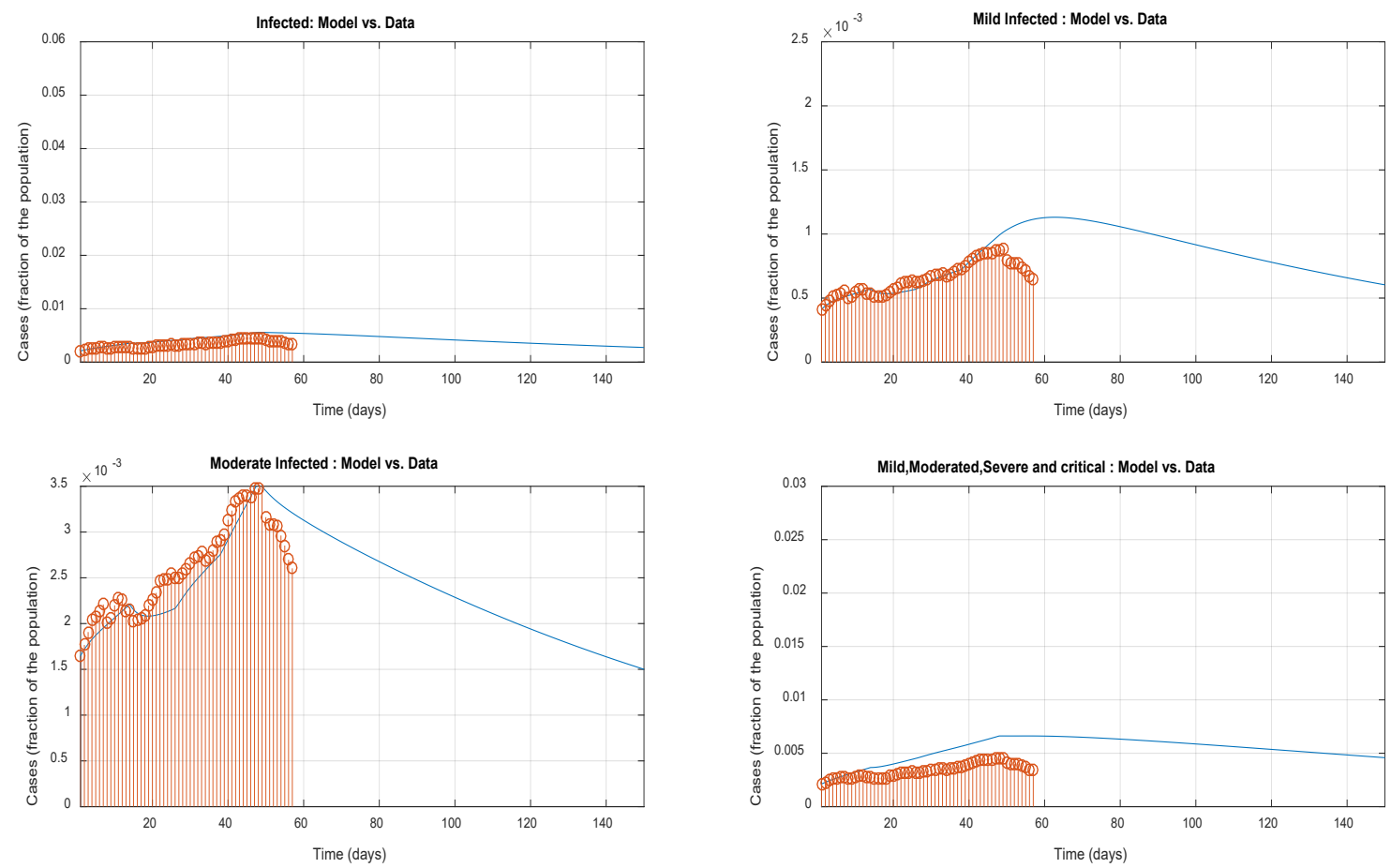

Figure $6 \mathrm{a}, \mathrm{b}$. The pandemic size of different clinical stage vs time - mild, moderate and all the cases together

\subsection{Sensitivity Analysis of the model with respect to varying parameters}

We analyzed the sensitivity of the model on infected, recovered and death cases with respect to transmission parameters, which would help the policy makers to plan appropriate strategies to mitigate the spread of the disease.

Fig 7 depicts 'how infected case changes with respect to transmitting parameters. Fig. 7 a-d illustrates how the nature of pandemic changes along with R 0 based on the transmitting parameters, $\alpha, \beta, \gamma, \delta$. The parameters are scaled using scaling factors $0.5,0.8,1.4,1.8$ and 2,2 on its current value during the period 5 .

*Correspondence to vinusherimon@yahoo.com 


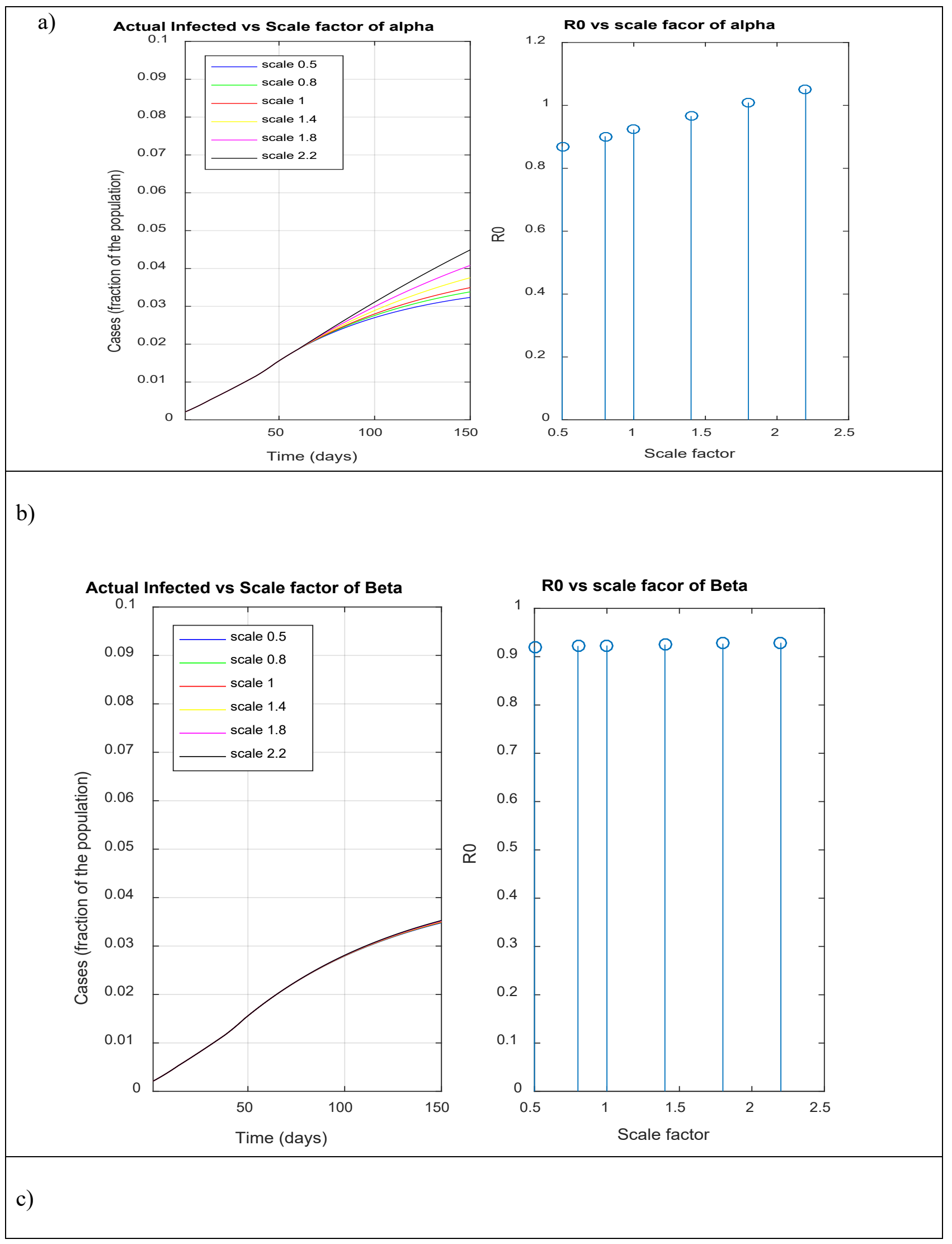

*Correspondence to vinusherimon@yahoo.com 


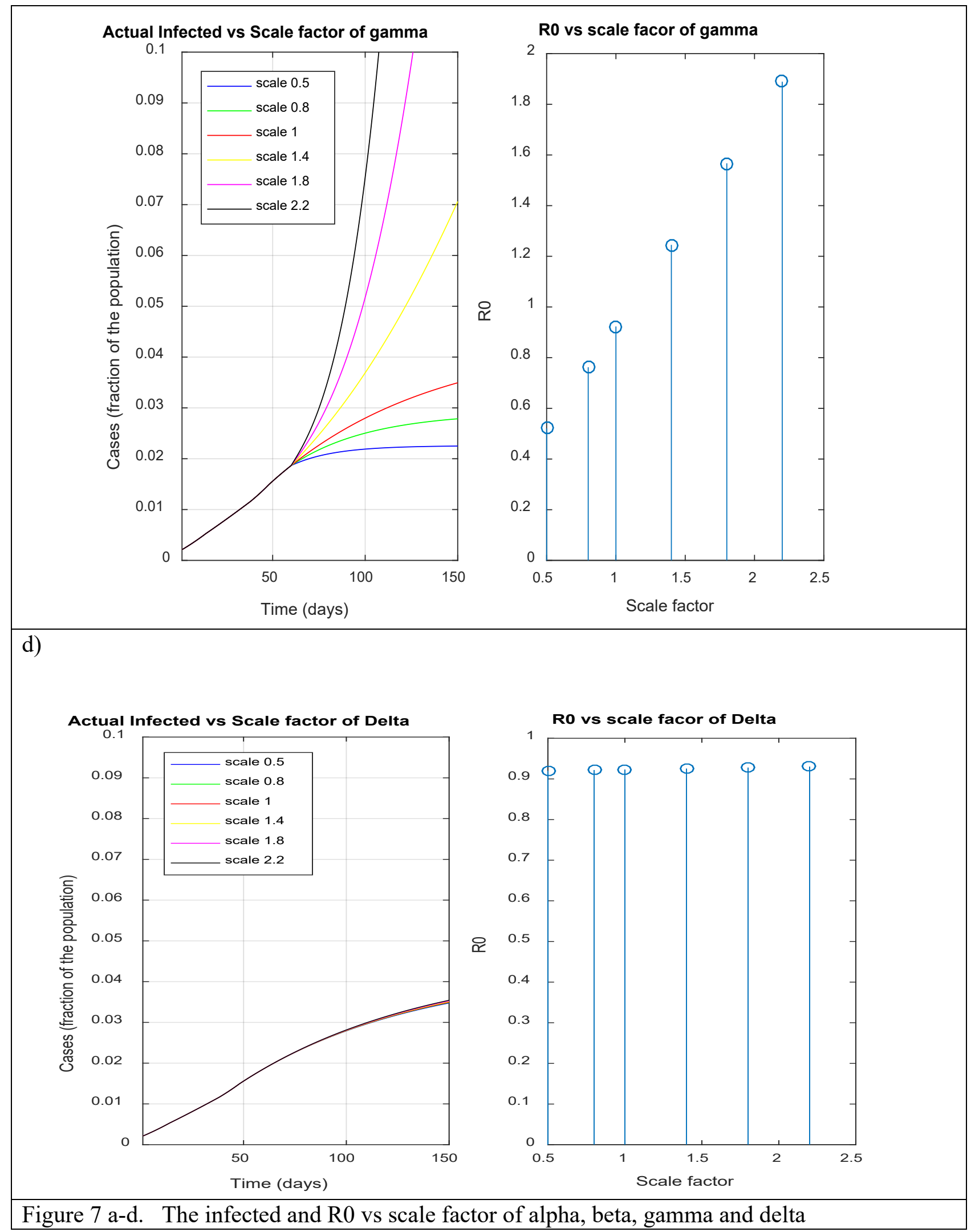

*Correspondence to vinusherimon@yahoo.com 
Fig 8 shows the sensitivity of transmission parameters with respect to the recovered cases.
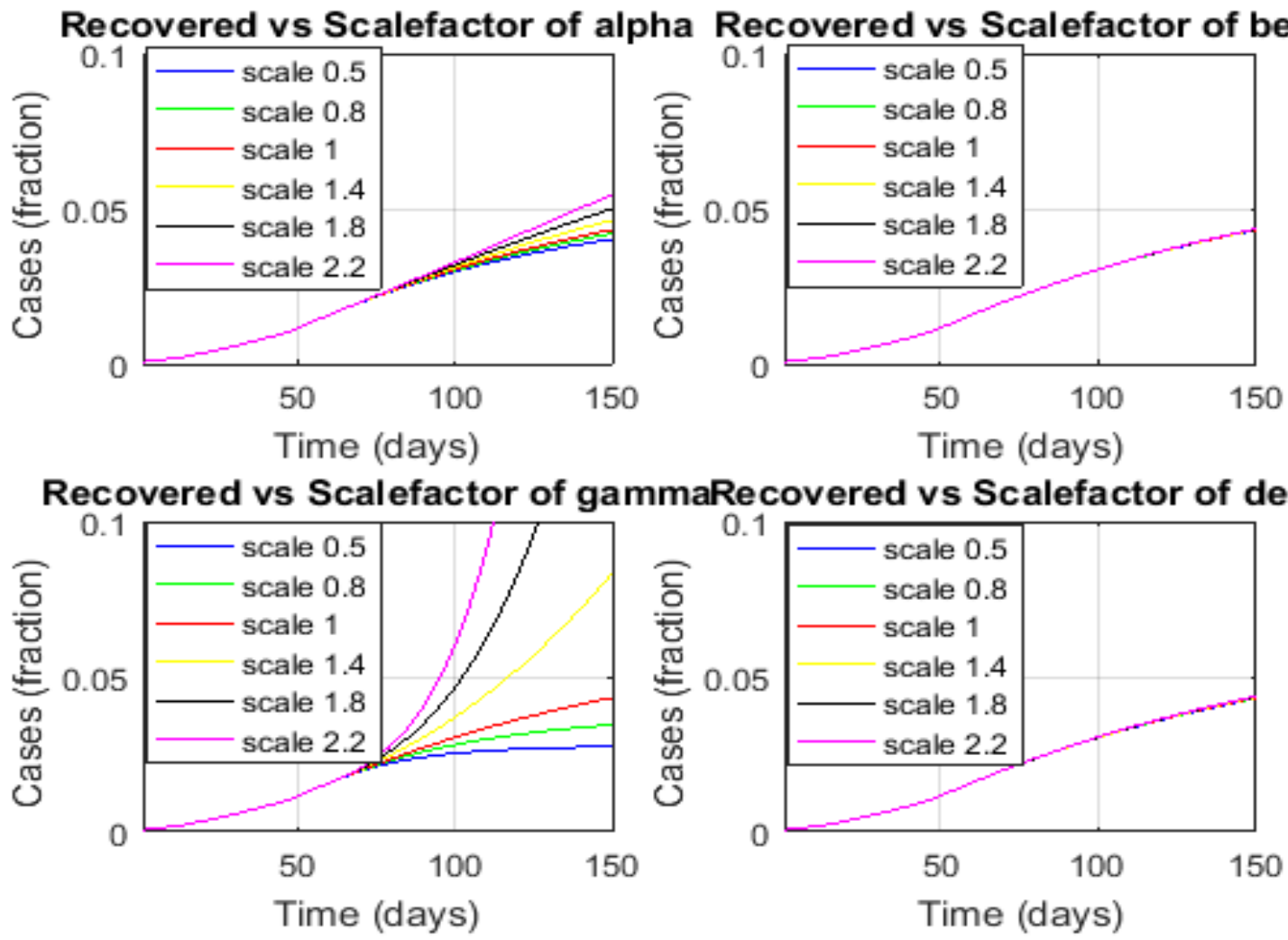

Figure 8 . The sensitivity of transmission parameters over recovered case

Fig 9 shows the sensitivity of transmission parameters with respect to the death cases.

*Correspondence to vinusherimon@yahoo.com 

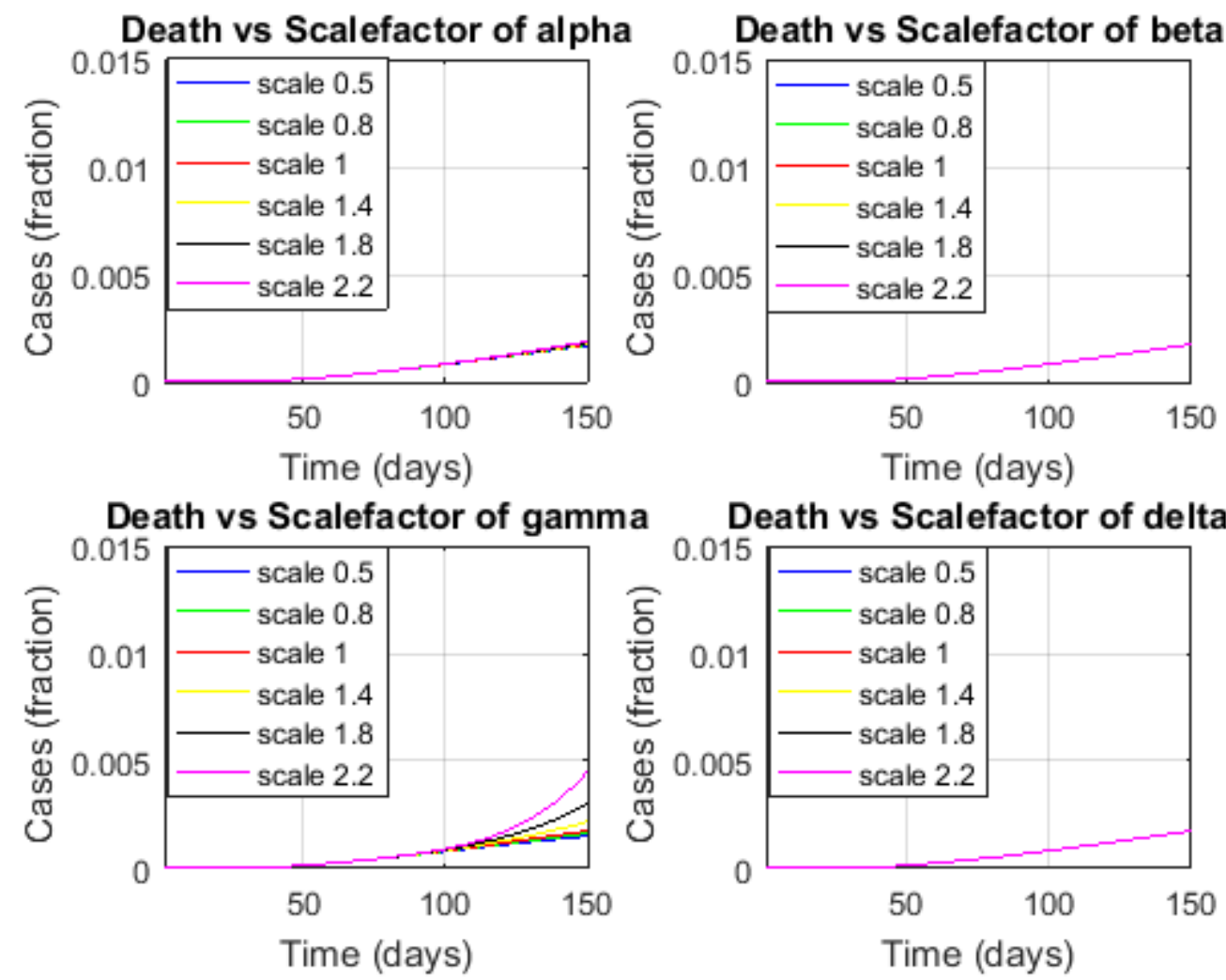

Figure 9. The sensitivity of transmission parameters over death cases

\section{Discussion}

In this research, the significant 15 parameters mentioned in the proposed model is calculated during the said period (Period 1 - Period 5) mentioned in Section 3, where significant change is observed in the data. And the corresponding basic reproduction number $\mathrm{R} 0$ is calculated which depicts the nature of the pandemic regarding the spread of the disease.

During Period 1, a partial lifting of the restrictions was observed after a 2-month lockdown period. The value of R0 is found to be 1.5802. During Period 2, ministry ensured strict social measures to stop the spreading of the disease. Timely instruction is given through official social media account [40], such as the importance of washing hands, social distancing etc. At the same time, authorities took necessary care to convey the people not to be panic so that they can reduce the over stress in this situation. Otherwise, ultimately it will affect the living conditions and moreover the business and working environments. More tests were conducted to avoid the panic in people. As a result a slight change resulted in social parameters like $\alpha, \beta$ and the new reproduction number becomes $\mathrm{R} 0=1.4811$.

During Period 3, isolation and quarantine policies were made stricter during the period from $28^{\text {th }}$ June- $10^{\text {th }}$ July 2020. Anyone who enters the Sultanate was subjected to quarantine for a 14-day period. The Omani residents were not permitted to go outside the Sultanate. The land and air borders were closed. Because of this strict isolation and quarantine process, and basic social distancing measures among people (such as washing hands often, not touching one's face, avoiding handshakes etc.) the value of R0 became 1.3071. During the period $11^{\text {th }}$ July-20 $0^{\text {th }}$ July 2020, due to the lack of strict lockdown and increase in the number of

*Correspondence to vinusherimon@yahoo.com 
random tests in the containment zones, more infected cases were reported. The Supreme Committee in Oman advised the public to wear face masks in public places, and for business establishments to ensure that the visitors also followed the required safety measures. The spread of the disease was little more during this period, which resulted in $\mathrm{R} 0$ value of 1.4392 .

During $21^{\text {st }}$ July $-30^{\text {th }}$ July, a nationwide lockdown came into effect. Travel between the governorates was not allowed. The emergency services such as ambulances, service vehicles that provide electricity and water maintenance, and vehicles belonging to the police and Armed Forces, were exempted from this ban. People remained indoors between 7 P.M. and 6 A.M. It was not permitted at all to go outside after 7 P.M., either on foot or in a vehicle. Such incidents were imposed with proper fines. Royal Oman Police set several checkpoints on the roads that connect diverse areas of the Sultanate, to ensure domestic travel restrictions. Working was no longer a valid reason for going out of the house; progressively non-indispensable activities were also stopped. As a result, at the end of July, R0 value became 0.9761. It shows that the restriction of the contact with each other in various form significantly brings down the value of R0, thereby decreasing the spread of the disease.

Based on the parameters obtained during period $5\left(21^{\text {st }}\right.$ July $-30^{\text {th }}$ July 2020$)$ and with the assumption that the policy will remain the same, we predicted the infected size, recovery size and death cases up to a period of 150 days. It is expected to have the number of cumulative infected cases as 236436 , number of recovery cases as 207839 and no of deaths as 9234 at the end of 150 days starting from June 04, 2020, provided no change in the policy decisions as on during period 5.

The sensitivity of the model is also analyzed on infected, recovered and death cases with respect to transmission parameters as given in Section 3. The sensitivity analysis on infected case shows that the transmission parameters alpha and gamma are very much sensitive to the spread of the disease. The reason for high sensitivity of gamma is due to the fact that these moderate category people (M) have higher probability rate of transmitting the disease as they are in infectious stage and they are isolated in the home only, not admitted in the hospital. The people in exposed (Et) category have higher rate of chance of contact with other people as at this stage disease not diagnosed and it is infectious at certain extent which result in higher sensitivity of alpha parameter. The lockdown and social distancing measures such as wearing mask, avoiding gathering, closing schools and mosques etc. will help significantly to reduce the value of these parameters.

The sensitivity analysis on recovered case shows that as the value of transmission parameters increases the number of recovered cases also increases. This is because the infected cases increase with the rise in parameters, accordingly more recovered case are also expected due to the dedicated service of our health centers. In sensitivity analysis of death cases, as parameter value increases, the number of death case may also increase. But due to our medical service, the rise in the value may not be alarming. So, in addition to fineness in our medical field, it is a vital role to frame an appropriate policy to reduce the value of parameter in order to control the disease like COVID-19 due to the absence of a specific vaccine for the disease.

It is observed that the transmission parameters are very much influenced by various remedial measures such as lockdown, social distancing and quarantine. This would reduce/increase the basic reproduction number which is the probability of disease transmission in a single contact multiplied by the average number of contacts per person. Since the transmission rate $\alpha$ is due to the contacts between susceptible and exposed (Et), its rate can be reduced through contact tracing and isolate them from the contact of others. The mass random test will also help to identify this category of exposed population (Et) who transmits the disease without showing any symptoms.

*Correspondence to vinusherimon@yahoo.com 


\section{Conclusion \& Future}

In this work we have developed a mathematical model to analyze the nature of the pandemic COVID-19 meaningfully on the data of Sultanate of Oman. The model is an extension of SEIR where we expanded the infected compartments into mild(A), moderate(M), severe(H) and critical(C), based on the clinical stages of infection. The exposed category is also extended to $\mathrm{E}_{\mathrm{N}}$ and $\mathrm{E}_{\mathrm{T}}$ where $\mathrm{E}_{\mathrm{T}}$ is an infectious stage. The parameters are estimated by fitting the data of Oman on the differential equations, and R0 is computed. The proof for the computation of R0, steady state analysis and final pandemic size equations are also shown in order to validate the model. The parameter value is justified with the effective actions taken by the government to lessen the spread of the disease. The sensitivity of the transmitting parameters is also identified which is a direct indicator of the impact of the strict or weak lockdown measures on the spread of the disease. It is observed that the transmitting parameters alpha and gamma are sensitive to the number of infected cases, and its value can be reduced by proper contact tracing mechanism and effective social distancing measures. In conclusion in Oman, there is no need for any complete lockdown as per the present situation. This research can be extended by analyzing the data of Oman by taking Wilayat wise or governorate wise data in Oman, and any country wise analysis. Also, the model can be extended by incorporating the impact of suitable vaccination, once it is discovered.

Funding: The research leading to these results has received Research Project Funding from The Research Council (TRC) of the Sultanate of Oman, under Commissioned Research Program, Contract No. TRC/CRP/HCT/COVID-19/20/06.

\section{Author Contributions}

AV conceived the idea, designed the model, formulated the equations, proofs, analysed the data and draft the article. SK involved in the design of mathematical equations and proofs. VS contributed to the literature review, article preparation and review. EL involved in the analysis. HH and JP have done the data collection. SS and HS reviewed the article.

\section{References}

[1] Van Doremalen N, Bushmaker T, Morris DH, Holbrook MG, Gamble A, Williamson BN, Tamin A, Harcourt JL, Thornburg NJ, Gerber SI, Lloyd-Smith JO. Aerosol and surface stability of SARS-CoV-2 as compared with SARS-CoV-1. New England Journal of Medicine. 2020 Apr 16; 382:1564-7.

[2] Xu R, Cui B, Duan X, Zhang P, Zhou X, Yuan Q. Saliva: potential diagnostic value and transmission of 2019-nCoV. International Journal of Oral Science. 2020 Apr 17; 12:1-6.

[3] Morawska L, Cao J. Airborne transmission of SARS-CoV-2: The world should face the reality. Environment International. 2020 Apr 10:105730.

[4] Li Q, Guan X, Wu P, Wang X, Zhou L, Tong Y, Ren R, Leung KS, Lau EH, Wong JY, Xing X. Early transmission dynamics in Wuhan, China, of novel coronavirus-infected pneumonia. New England Journal of Medicine. 2020 Jan 29.

[5] Huang C, Wang Y, Li X, Ren L, Zhao J, Hu Y, Zhang L, Fan G, Xu J, Gu X, Cheng Z. Clinical features of patients infected with 2019 novel coronavirus in Wuhan, China. The lancet. 2020 Feb 15; 395:497506.

*Correspondence to vinusherimon@yahoo.com 
[6] WHO Emergency Committee regarding the outbreak of Coronavirus disease 2019 (COVID-19), [Accessed 11th March 2020]. https://www.who.int/dg/speeches/detail/who-director-general-s-openingremarks-at-the-media-briefing-on-covid-19---11-march-2020.

[7] Lewnard JA, Lo NC. Scientific and ethical basis for social-distancing interventions against COVID-19. The Lancet. Infectious diseases. 2020 June; 20:631.

[8] Worldometer. https://www.worldometers.info/coronavirus/country/oman/ [Accessed on 05 September 2020]

[9] Bernoulli D. An attempt at a new analysis of mortality caused by smallpox. Theses of Mathematics and Physics, Royal Academy of Sciences 1: 1-45,1766

[10] Ross R. The prevention of malaria. London: John Murray. 651-686, 1911

[11] Macdonald G. The analysis of equilibrium in malaria. Tropical diseases bulletin. 1952 Sep; 49:813.

[12] Kermack WO, McKendrick AG. A contribution to the mathematical theory of epidemics. Proceedings of the royal society of london. Series A, Containing papers of a mathematical and physical character. 1927 Aug 1; 115:700-21.

[13] Hethcote HW. The mathematics of infectious diseases. SIAM review. 2000; 42:599-653.

[14] de Jong MC, Hagenaars TH. Modelling control of avian influenza in poultry: the link with data. Revue scientifique et technique/Office International des Epizooties. 2009; 28:371-7.

[15] Browne C, Gulbudak H, Webb G. Modeling contact tracing in outbreaks with application to Ebola. Journal of theoretical biology. 2015 Nov 7; 384: 33-49.

[16] Anastassopoulou C, Russo L, Tsakris A, Siettos C. Data-based analysis, modelling and forecasting of the COVID-19 outbreak. PloS one. 2020 Mar 31;15: e0230405.

[17] Casella F. Can the COVID-19 epidemic be managed on the basis of daily data? arXiv preprint arXiv:2003.06967. 2020 Mar 16.

[18] Giordano G, Blanchini F, Bruno R, Colaneri P, Di Filippo A, Di Matteo A, Colaneri M. Modelling the COVID-19 epidemic and implementation of population-wide interventions in Italy. Nature Medicine. 2020 Apr 22:1-6.

[19] Ndairou F, Area I, Nieto JJ, Torres DF. Mathematical modeling of COVID-19 transmission dynamics with a case study of Wuhan. Chaos, Solitons \& Fractals. 2020 Apr 27:109846.

[20] Chatterjee K, Chatterjee K, Kumar A, Shankar S. Healthcare impact of COVID-19 epidemic in India: A stochastic mathematical model. Medical Journal Armed Forces India. 2020 Apr 2.

[21] Zeb A, Alzahrani E, Erturk VS, Zaman G. Mathematical model for coronavirus disease 2019 (COVID-19) containing isolation class. BioMed research international. 2020 Jun 25;2020.

[22] Khamis F, Al Rashidi B, Al-Zakwani I, Al Wahaibi AH, Al Awaidy ST. Epidemiology of COVID19 infection in Oman: Analysis of the first 1304 cases. Oman Medical Journal. 2020 May;35: e141.

[23] Wang, Jiancong, Mouqing Zhou, and Fangfei Liu. "Exploring the Reasons for Healthcare Workers Infected with Novel Coronavirus Disease 2019 (COVID-19) in China." Journal of Hospital Infection 0 (0). https://doi.org/10.1016/j.jhin.2020.03.002,2020

[24] Van den Driessche P, Watmough J. Reproduction numbers and sub-threshold endemic equilibria for compartmental models of disease transmission. Mathematical biosciences. 2002 Nov 1; 180:29-48.

[25] World Health Organization. Report of the WHO-China Joint Mission on Coronavirus Disease 2019 (COVID-19) 16-24 February 2020 [Internet]. Geneva: World Health Organization; 2020 Available from: https://www.who.int/docs/default-source/coronaviruse/who-china-joint-mission-on-covid-19finalreport.pdf

[26] Yu P, Zhu J, Zhang Z, Han Y. A familial cluster of infection associated with the 2019 novel coronavirus indicating possible person-to-person transmission during the incubation period. The Journal of infectious diseases. 2020 May 11; 221:1757-61.

*Correspondence to vinusherimon@yahoo.com 
[27] Huang R, Xia J, Chen Y, Shan C, Wu C. A family cluster of SARS-CoV-2 infection involving 11 patients in Nanjing, China Lancet Infect Dis 2020 doi: 10.1016/ S1473-3099(20)30147-X

[28] Pan X, Chen D, Xia Y, Wu X, Li T. Xueting Ou, Liyang Zhou, and Jing Liu. 2020.“Asymptomatic cases in a family cluster with SARS-CoV-2 infection.". The Lancet Infectious Diseases.;20(4):410-1.

[29] Ling A, Leo Y. Potential presymptomatic transmission of SARS-CoV-2, Zhejiang province, China. Emerg Infect Dis. 2020;26(5):1052-4.

[30] Kimball A, Hatfield KM, Arons M, James A, Taylor J, Spicer K, Bardossy AC, Oakley LP, Tanwar S, Chisty Z, Bell JM. Asymptomatic and presymptomatic SARS-CoV-2 infections in residents of a longterm care skilled nursing facility-King County, Washington, March 2020. Morbidity and Mortality Weekly Report. 2020 Apr 3; 69:377.

[31] Liu J, Liao X, Qian S, Yuan J, Wang F, Liu Y, Wang Z, Wang FS, Liu L, Zhang Z. Community transmission of severe acute respiratory syndrome coronavirus 2, Shenzhen, China, 2020.

[32] Chan JF, Yuan S, Kok KH, To KK, Chu H, Yang J, Xing F, Liu J, Yip CC, Poon RW, Tsoi HW. A familial cluster of pneumonia associated with the 2019 novel coronavirus indicating person-to-person transmission: a study of a family cluster. The Lancet. 2020 Feb 15; 395:514-23.

[33] Bai Y, Yao L, Wei T, Tian F, Jin DY, Chen L, Wang M. Presumed asymptomatic carrier transmission of COVID-19. Jama. 2020 Apr 14; 323:1406-7.

[34] Huang C, Wang Y, Li X, Ren L, Zhao J, Hu Y, Zhang L, Fan G, Xu J, Gu X, Cheng Z. Clinical features of patients infected with 2019 novel coronavirus in Wuhan, China. The lancet. 2020 Feb 15; 395:497-506.

[35] Burke RM. Active monitoring of persons exposed to patients with confirmed COVID-19-United States, January-February 2020. MMWR. Morbidity and mortality weekly report. 2020;69.

[36] Ong SW, Tan YK, Chia PY, Lee TH, Ng OT, Wong MS, Marimuthu K. Air, surface environmental, and personal protective equipment contamination by severe acute respiratory syndrome coronavirus 2 (SARS-CoV-2) from a symptomatic patient. Jama. 2020 Apr 28; 323:1610-2.

[37] Liu Y, Yan LM, Wan L, Xiang TX, Le A, Liu JM, Peiris M, Poon LL, Zhang W. Viral dynamics in mild and severe cases of COVID-19. The Lancet Infectious Diseases. 2020 Mar 19.

[38] Wolfel R, Corman V, Guggemos W. Virological assessment of hospitalized cases of coronavirus disease, Nature volume 581, p 465-469(2020).

[Dataset][39] Ministry of Health Oman. https://www.moh.gov.om/en/-50, [Accessed by 30 July 2020] [Dataset][40]Ministry of Health Oman Twitter Account: https://witter.com/OmaniMOH [Accessed by 30 July 2020]

*Correspondence to vinusherimon@yahoo.com 
Figures

\section{Data Streams and the Severity Pyramid}

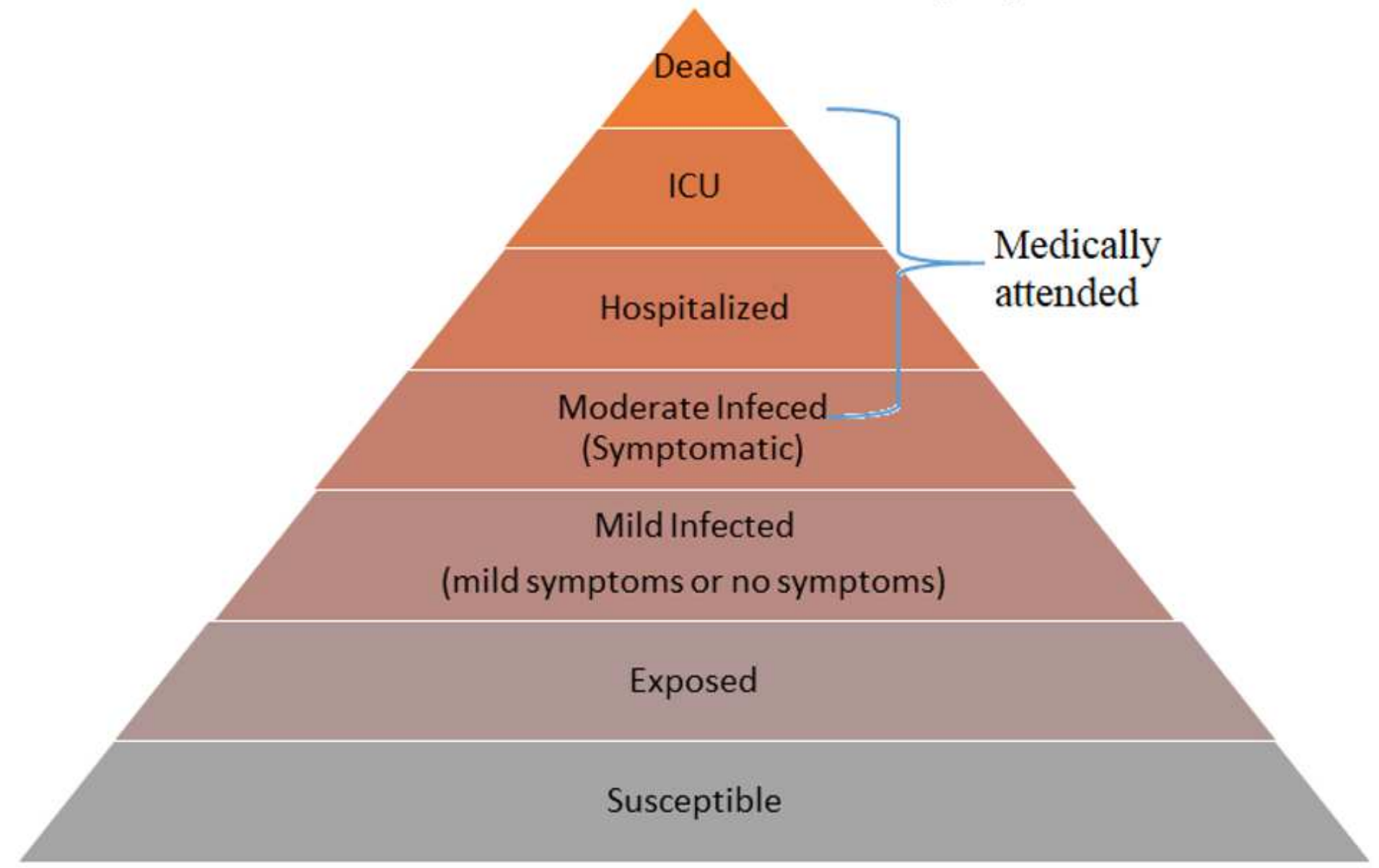

Figure 1

The different stages of the compartment model 


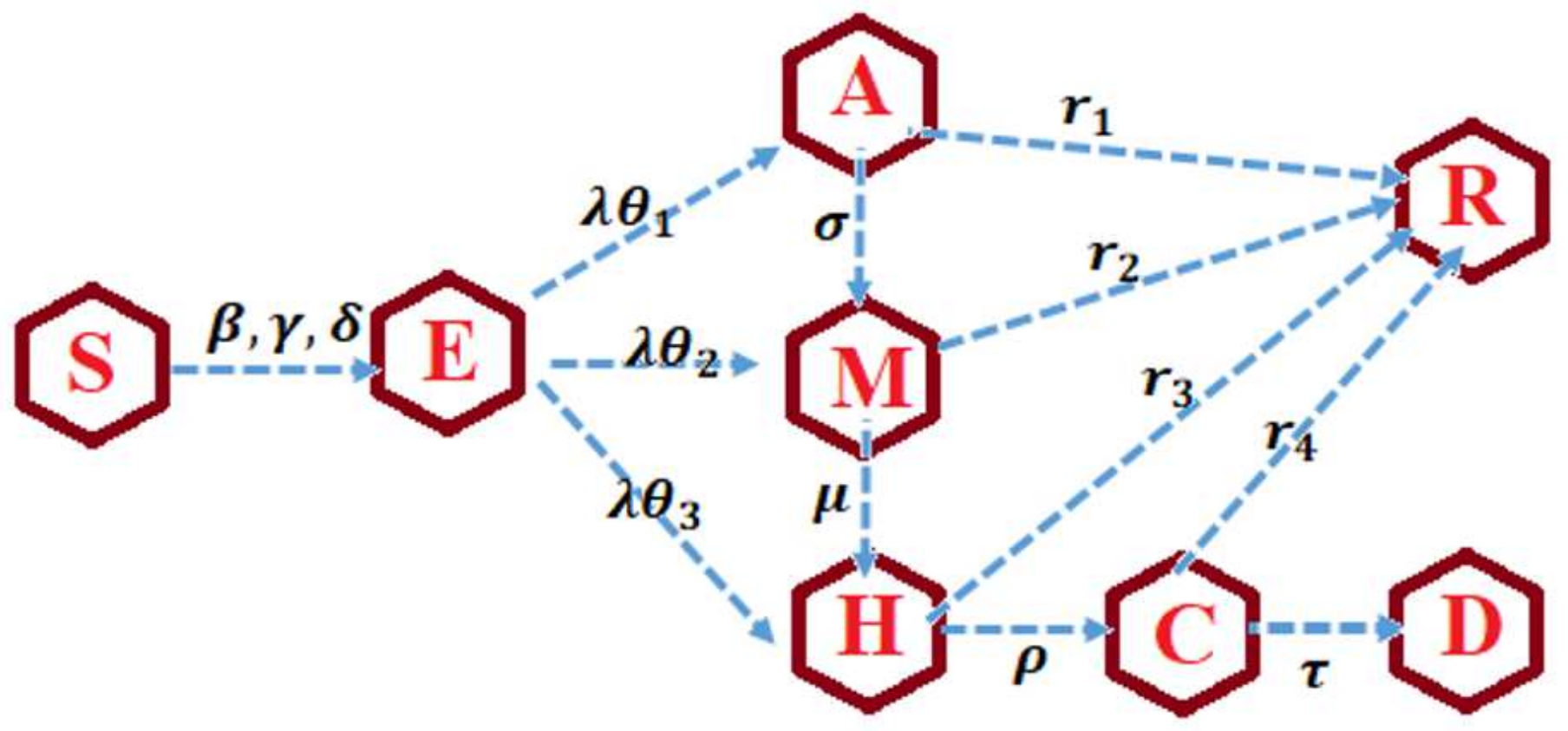

Figure 2

The overview of the model
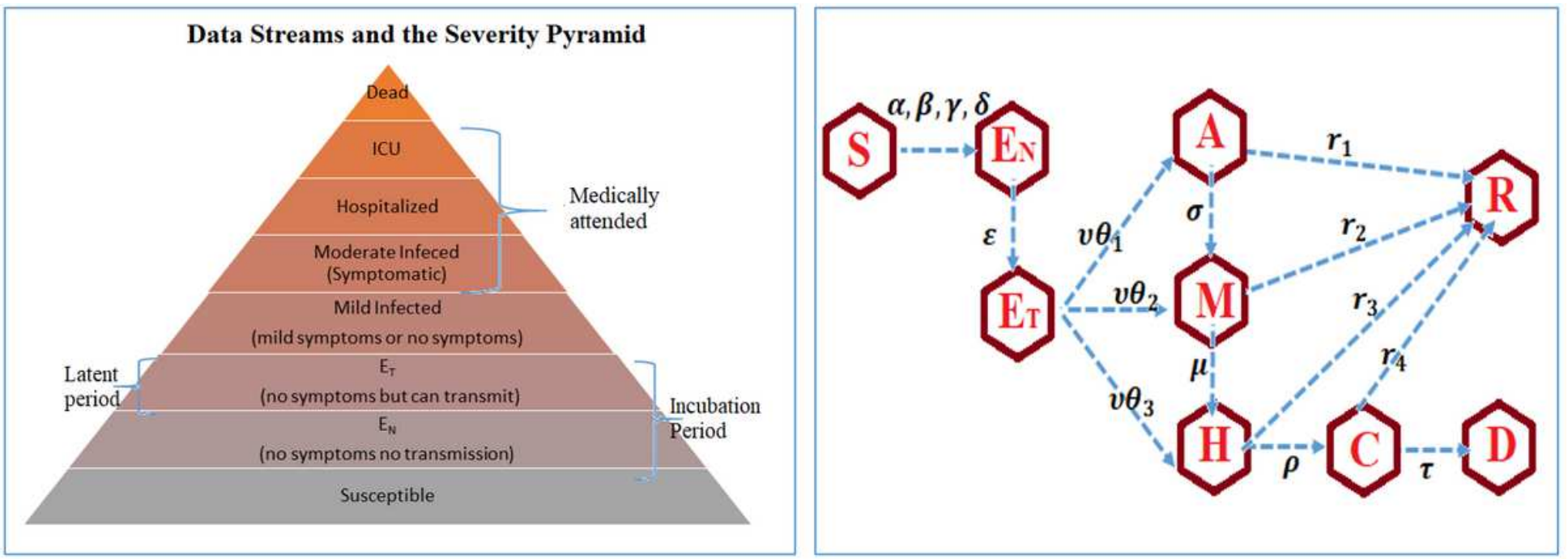

Figure 3

The extension of the model by including exposed period 
R0 over different period
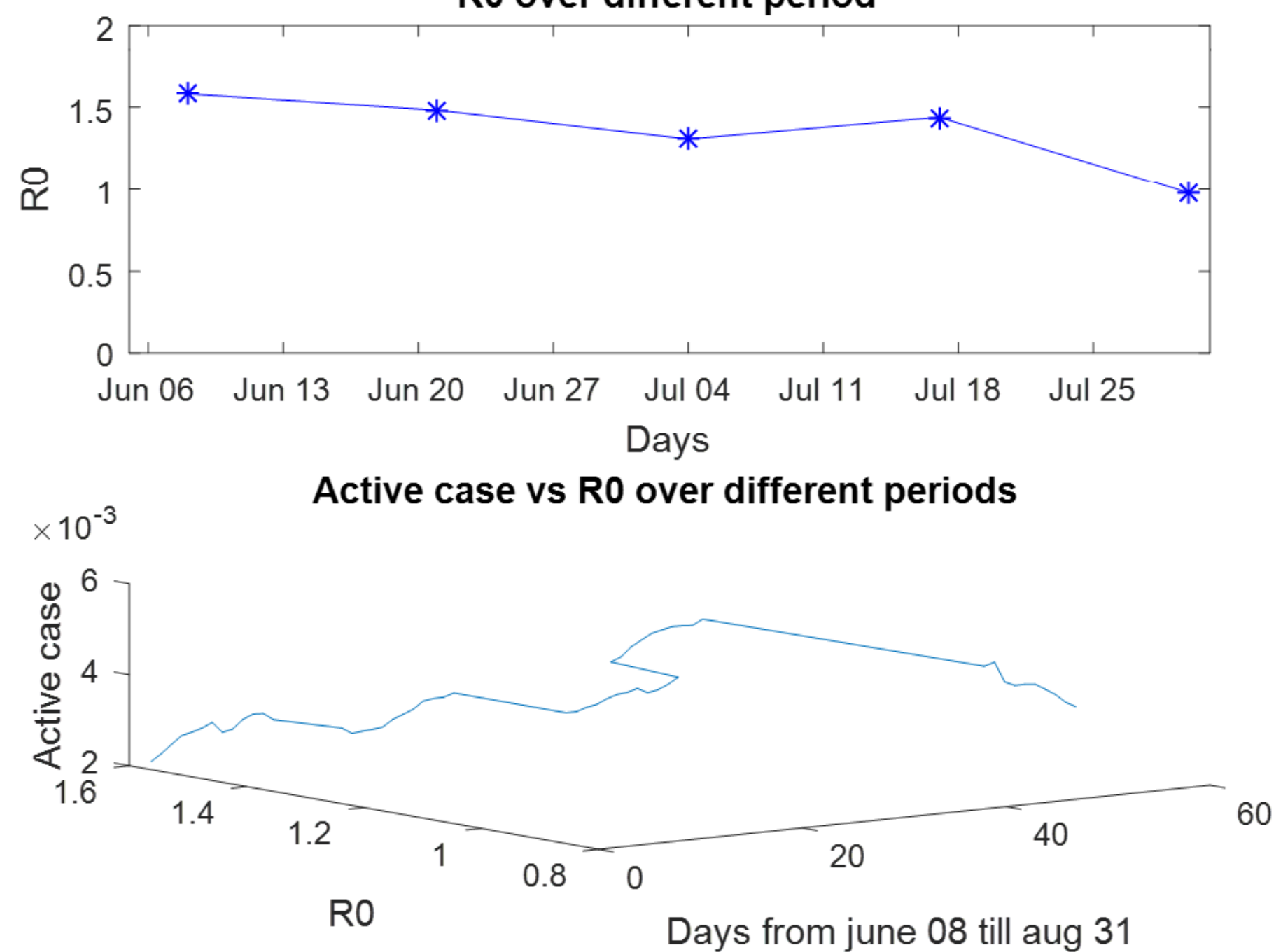

Figure 4

$\mathrm{R} 0$ and Active case vs Time 

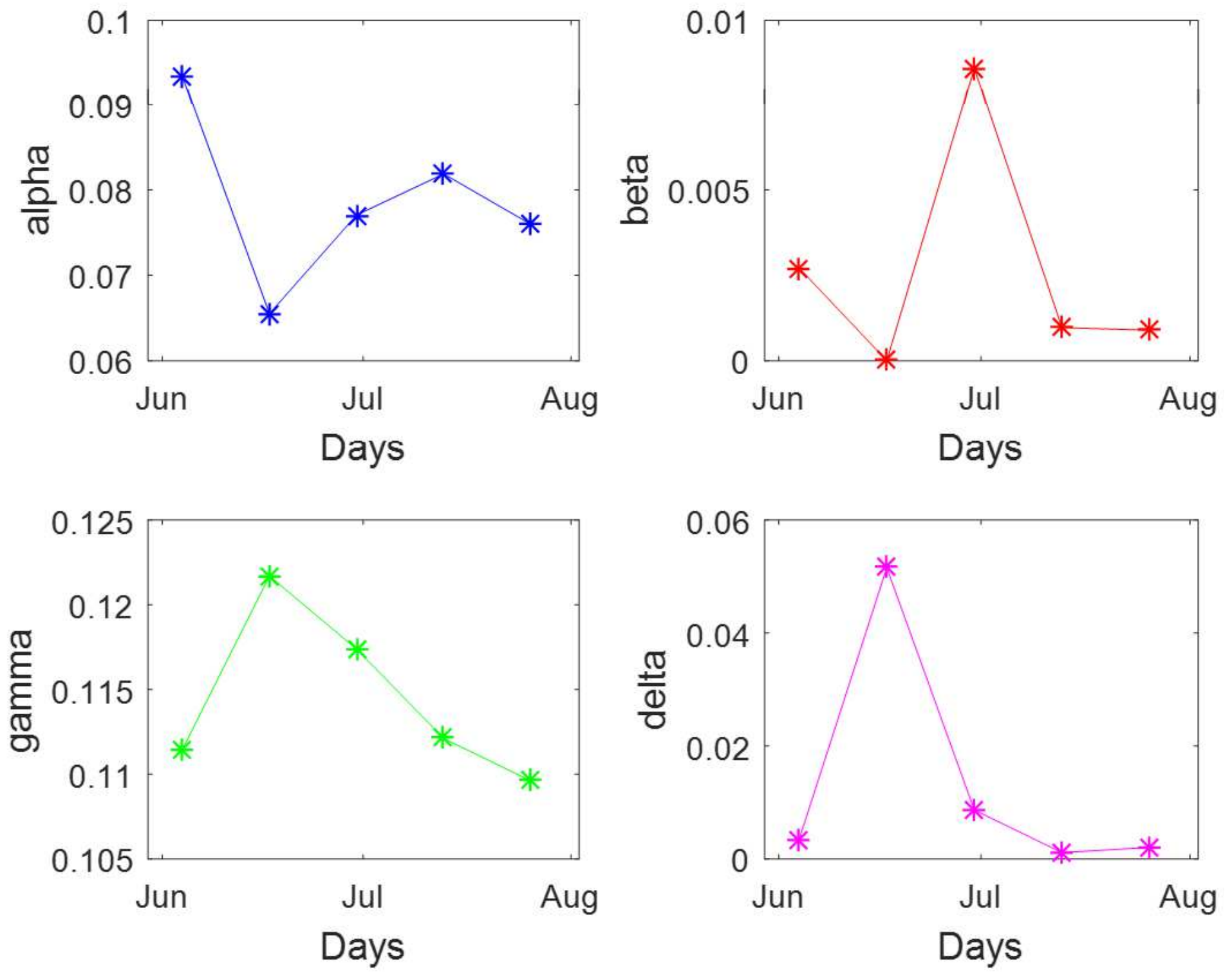

Figure 5

The transmission parameters vs time
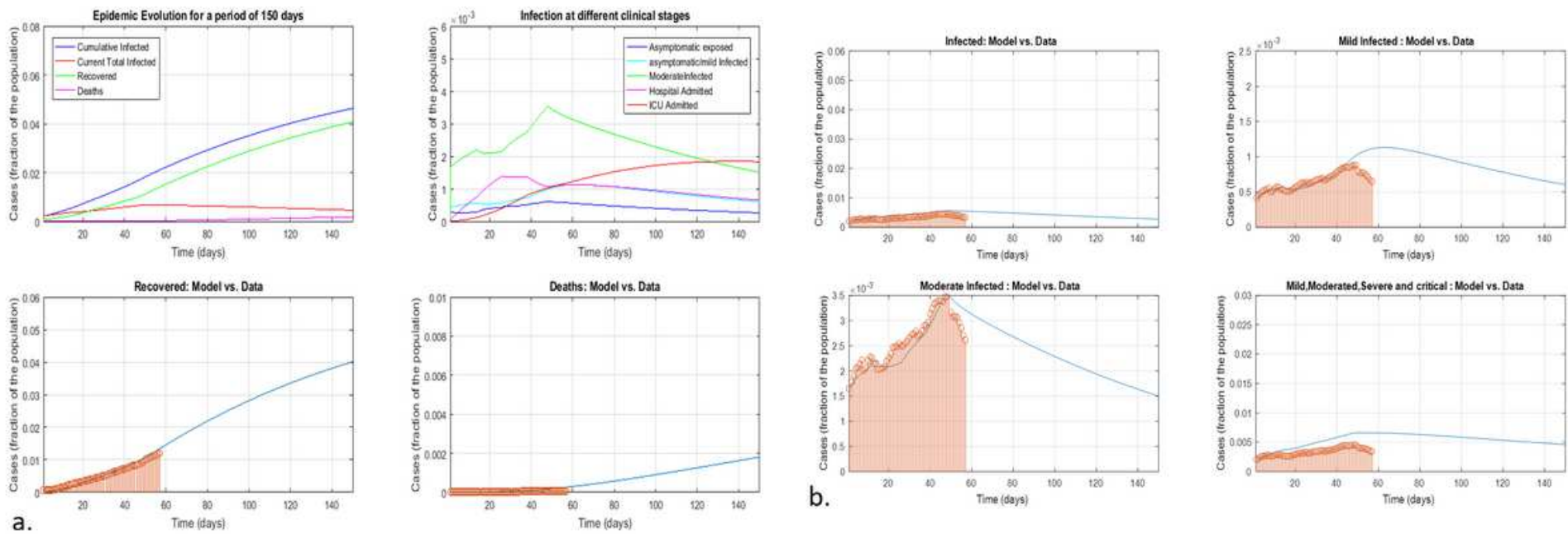
Figure 6

a. The pandemic size of different clinical stage vs time - infected case, recovered case and death case b. The pandemic size of different clinical stage vs time - mild, moderate and all the cases together
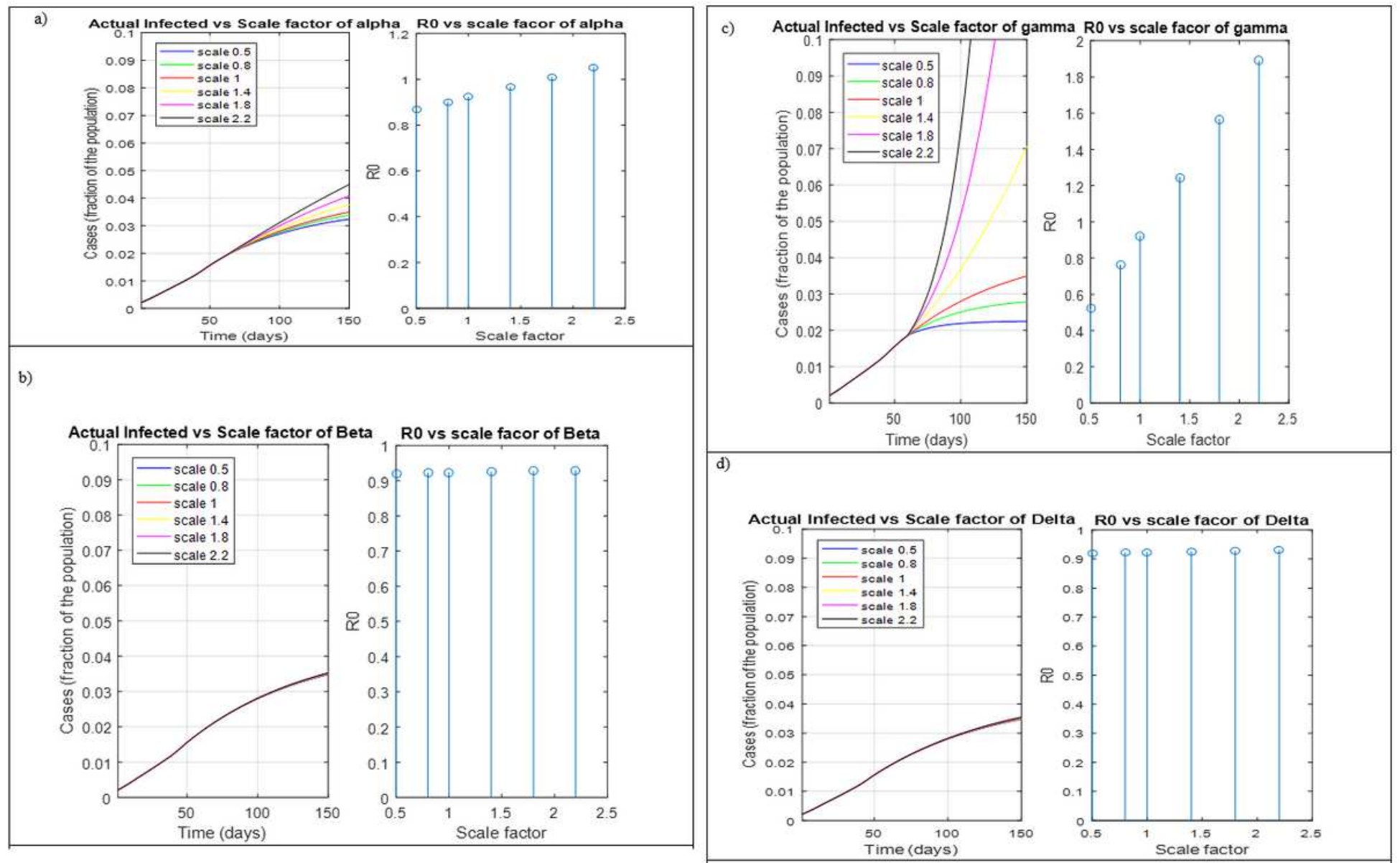

Figure 7

a-d. The infected and RO vs scale factor of alpha, beta, gamma and delta 

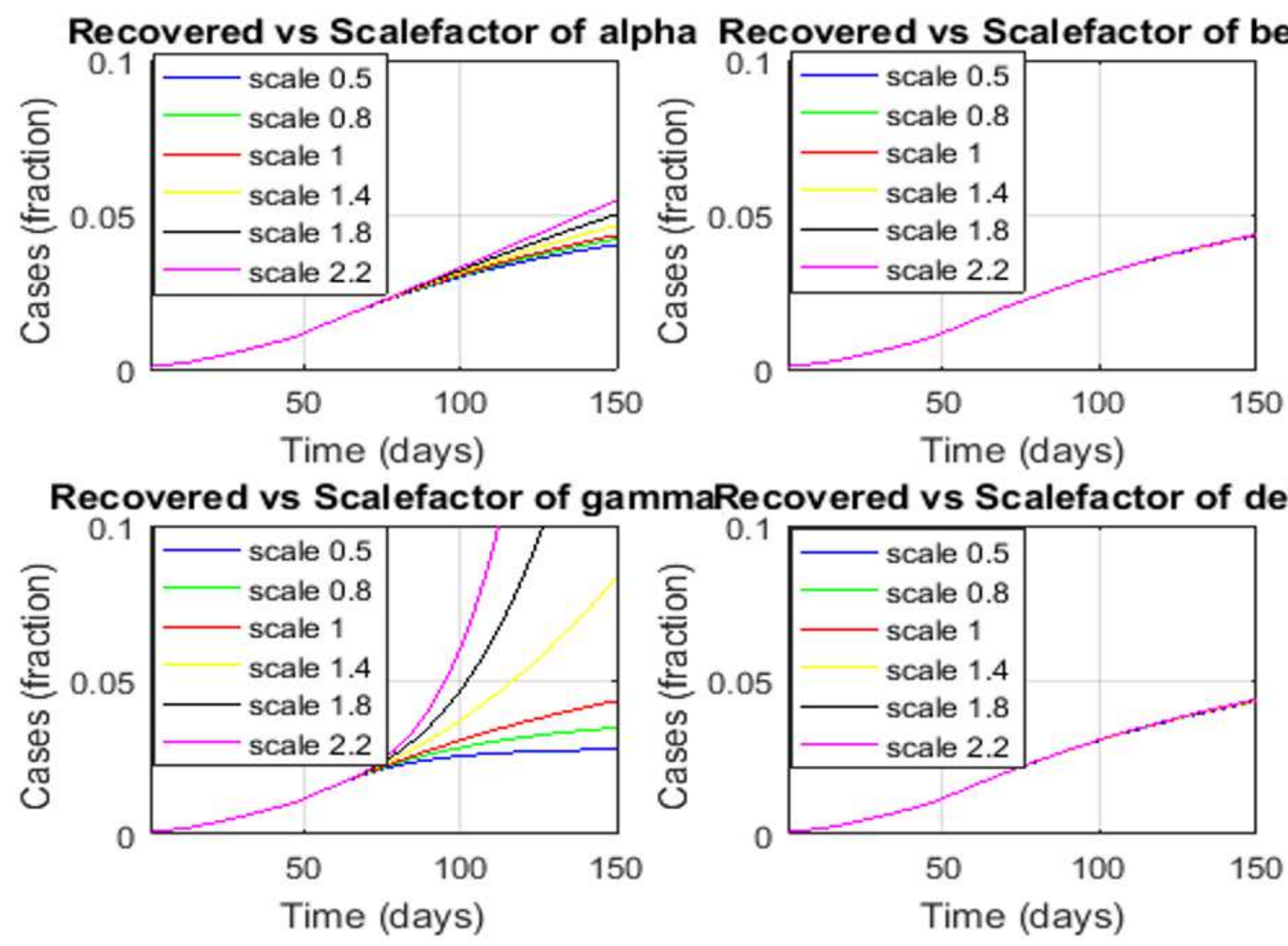

Figure 8

The sensitivity of transmission parameters over recovered case 

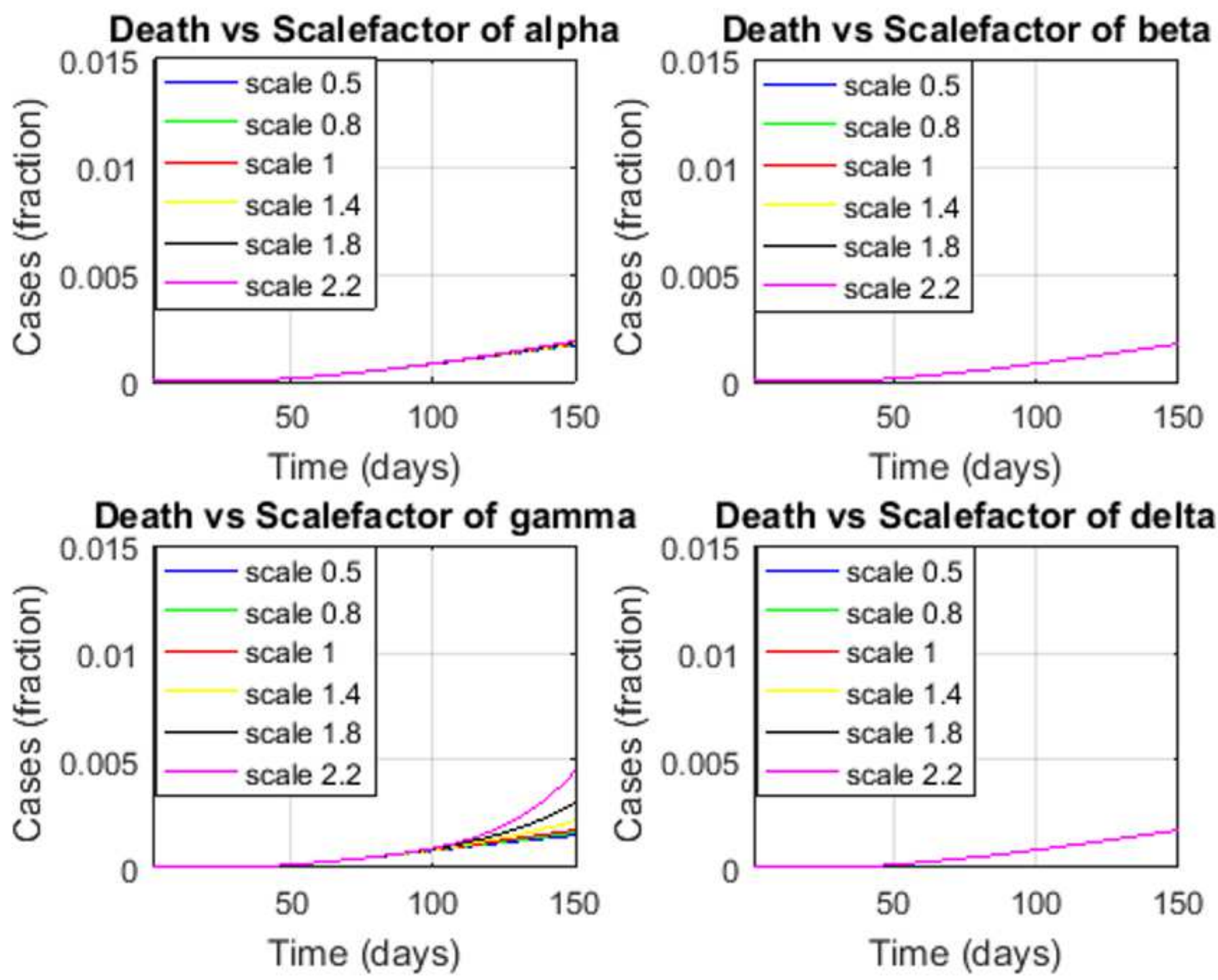

Figure 9

The sensitivity of transmission parameters over death cases 